\title{
Understanding advances in the simulation of intraseasonal variability in the ECMWF model. Part II: the application of process- based diagnostics
}

Article

Published Version

Hirons, L. C., Inness, P., Vitart, F. and Bechtold, P. (2013) Understanding advances in the simulation of intraseasonal variability in the ECMWF model. Part II: the application of process-based diagnostics. Quarterly Journal of the Royal Meteorological Society, 139 (675). pp. 1427-1444. ISSN 1477870X doi: https://doi.org/10.1002/qj.2059 Available at https://centaur.reading.ac.uk/31399/

It is advisable to refer to the publisher's version if you intend to cite from the work. See Guidance on citing.

To link to this article DOI: http://dx.doi.org/10.1002/qj.2059

Publisher: Royal Meteorological Society

All outputs in CentAUR are protected by Intellectual Property Rights law, including copyright law. Copyright and IPR is retained by the creators or other copyright holders. Terms and conditions for use of this material are defined in the End User Agreement. 


\section{www.reading.ac.uk/centaur}

\section{CentAUR}

Central Archive at the University of Reading

Reading's research outputs online 


\title{
RMetS
}

Royal Meteorological Society

\section{Understanding advances in the simulation of intraseasonal variability in the ECMWF model. Part II: The application of process-based diagnostics}

\author{
L. C. Hirons ${ }^{\star}$, P. Inness, F. Vitart and P. Bechtold \\ Department of Meteorology, University of Reading, UK
}

${ }^{*}$ Correspondence to: L. C. Hirons, Department of Meteorology, University of Reading, Earley Gate, PO Box 243, Reading RG6 6BB, UK. E-mail: 1.c.hirons@reading.ac.uk

In Part I of this study it was shown that moving from a moisture-convergent- to a relative-humidity-dependent organized entrainment rate in the formulation for deep convection was responsible for significant advances in the simulation of the Madden-Julian Oscillation (MJO) in the ECMWF model. However, the application of traditional MJO diagnostics were not adequate to understand why changing the control on convection had such a pronounced impact on the representation of the MJO.

In this study a set of process-based diagnostics are applied to the hindcast experiments described in Part I to identify the physical mechanisms responsible for the advances in MJO simulation. Increasing the sensitivity of the deep convection scheme to environmental moisture is shown to modify the relationship between precipitation and moisture in the model. Through dry-air entrainment, convective plumes ascending in low-humidity environments terminate lower in the atmosphere. As a result, there is an increase in the occurrence of cumulus congestus, which acts to moisten the mid troposphere. Due to the modified precipitation-moisture relationship more moisture is able to build up, which effectively preconditions the tropical atmosphere for the transition to deep convection. Results from this study suggest that a tropospheric moisture control on convection is key to simulating the interaction between the convective heating and the large-scale wave forcing associated with the MJO. Copyright (c) 2012 Royal Meteorological Society

Key Words: numerical weather prediction; Madden-Julian Oscillation; convective parametrization

Received 9 May 2012; Revised 14 August 2012; Accepted 28 September 2012; Published online in Wiley Online Library

Citation: Hirons LC, Inness P, Vitart F, Bechtold P. 2012. Understanding advances in the simulation of intraseasonal variability in the ECMWF model. Part II: The application of process-based diagnostics. Q. J. R. Meteorol. Soc. DOI:10.1002/qj.2059

1. Introduction

Part I of this study (Hirons et al., 2012, hereafter referred to as $\mathrm{H} 12$ ) examined the representation of the Madden-Julian oscillation (MJO) in the European Centre for MediumRange Weather Forecasts (ECMWF) Integrated Forecasting System (IFS). Hindcast experiments (CONV, ENTRN and CAPE; Table 1, H12), which differ only in their formulation of convection, were compared with control versions of the IFS (Cy31r1 and OPER) and observations during the Year of Tropical Convection (YOTC) period from May 2008 to April 2009. The hindcast experiments were designed to test the sensitivity of MJO simulation to recent modifications to the model physics introduced in Cycle 32r3 (Cy32r3) of the IFS. Bechtold et al. (2008) (hereafter B08) showed that changes to the convection and vertical diffusion schemes led to a more realistic representation of convectively coupled equatorial Kelvin and Rossby waves, 
Table 1. Summary of convective parametrization in experiments and comparisons which isolate the effects of individual convection modifications.

\begin{tabular}{ll}
\hline Experiment & Convection: $\tau, \epsilon_{\mathrm{org}}$ \\
\hline Cy31r1 & $3600 \mathrm{~s}, \epsilon_{\mathrm{org}}^{\mathrm{MC}}$ \\
OPER & $720-10800 \mathrm{~s}, \epsilon_{\mathrm{org}}^{\mathrm{RH}}$ \\
CONV & $720 \mathrm{~s}, \epsilon_{\mathrm{org}}^{\mathrm{MC}}$ \\
ENTRN & $720-10800 \mathrm{~s}, 0.5 \times \epsilon_{\mathrm{org}}^{\mathrm{RH}}$ \\
CAPE & $720 \mathrm{~s}, \epsilon_{\mathrm{org}}^{\mathrm{RH}}$ \\
\hline Convection modification & IFS comparison \\
\hline Cy32r3 $\left(\epsilon_{\mathrm{org}}^{\mathrm{RH}} \& \tau\right)$ & OPER-CONV \\
$\epsilon_{\mathrm{org}}$ formulation & CAPE-CONV \\
$\tau$ & OPER-CAPE \\
$\epsilon_{\mathrm{org}}^{\mathrm{RH}}$ rate & OPER-ENTRN \\
\hline
\end{tabular}

as well as improving the simulation of tropical intraseasonal variability associated with the MJO. H12 established that the improved representation of the MJO in the IFS could be directly attributed to modifications to the convection scheme. The modified convective parametrization included two changes to the formulation of deep convection: (a) a variable CAPE adjustment time-scale, $\tau$; and (b) changing the formulation for organized entrainment from a moistureconvergent-dependent formulation $\left(\epsilon_{\mathrm{org}}^{\mathrm{MC}}\right)$ to one dependent on environmental humidity $\left(\epsilon_{\mathrm{org}}^{\mathrm{RH}}\right)$.

When multiple changes are implemented in an NWP model, it is usually only possible to speculate about the effect of individual modifications. However, the hindcast experiments described in $\mathrm{H} 12$ present a unique opportunity to isolate the effect of individual components of the IFS convective parametrization on the simulation of the MJO. It was shown in $\mathrm{H} 12$ that increasing the sensitivity of convection to environmental moisture led to an increase in the variance of convective activity and eastward propagating spectral power associated with the MJO. Although the application of recognized MJO diagnostics (Waliser et al., 2009) in H12 enabled the full description of the representation of the MJO it did not give insight into the physical mechanisms responsible for the observed advances in simulation. Therefore, this paper addresses the conclusion from $\mathrm{H} 12$, that a more process-based approach should be taken.

After a brief summary of the experimental set-up that was applied in H12 (section 2.1) and the analysis techniques used in this paper (sections 2.2-2.3), the focus will turn to the effect that the modified convective parametrization had on the mean state of the IFS (sections 3.1-3.3). The results of applying the process-based diagnostics introduced in section 2.3 will be presented in sections $4.1-4.4$. Finally, discussion of the results and overall conclusions will be presented in section 5 .

\section{Methodology}

\subsection{Summary of experiments}

The model description and experimental set-up are described fully in section 2.1 of H12. However, as a summary Table 1 shows how the convection formulation differs between experiments and what comparisons between experiments reveal about individual modifications.
Comparing (a) OPER and CONV, (b) CAPE and CONV and (c) OPER and CAPE isolates the effect of (a) the entire modified convective parametrization $\left(\epsilon_{\mathrm{org}}^{\mathrm{RH}}\right.$ formulation and $\tau$ ), (b) the $\epsilon_{\text {org }}$ formulation and (c) the variable $\tau$. The inclusion of the ENTRN experiment addresses the relative importance of the rate versus formulation of organized entrainment.

\subsection{The mean state}

The mean state of a model is thought to be important to the dynamics of the MJO (e.g. Ray et al., 2011). Modelling studies have shown that improving the quality of the background state, through flux-adjustment techniques, can lead to a better representation of the MJO (e.g. Inness et al., 2003; Sperber et al., 2005). For example, Inness et al. (2003) showed that mean low-level and surface westerlies favour MJO development, a hypothesis confirmed in observations by Zhang et al. (2006). Furthermore, the background state of a model is crucial to instability theories of the MJO, such as wave-CISK, where the distribution of lowlevel environmental moisture defines the growth rate and propagation speed of the MJO.

To understand why the introduction of the modified parametrization of convection in Cy32r3 so dramatically improved the simulation of the $\mathrm{MJO}$, it is important to quantify the impact of the new scheme on the basic state of the model. In an NWP model like the IFS, the basic state is not constant but evolves with increasing forecast lead time. The aim of the analysis in sections 3.1-3.3 is to understand whether the new convection scheme, or more specifically the relative-humidity-dependent formulation for entrainment $\left(\epsilon_{\mathrm{org}}^{\mathrm{RH}}\right)$, has resulted in a favourable background state for the initiation and evolution of the MJO.

\subsection{Process-based diagnostics}

The MJO diagnostics applied in $\mathrm{H} 12$ showed that modifications to the convective parametrization in Cy32r3 led to advances in the simulation of the MJO (summarized in Figure 7, H12). Unique to $\mathrm{H} 12$ was the attribution of those improvements in MJO simulation to $\epsilon_{\mathrm{org}}^{\mathrm{RH}}$. Despite this attribution, the MJO diagnostics applied in $\mathrm{H} 12$ have not shown why changing from a moisture-convergence- to a relative-humidity-dependent formulation for organized entrainment resulted in such pronounced advances in MJO simulation. Therefore, a set of process-based diagnostics, (a) - (d) described below, are applied to the IFS output in sections $4.1-4.4$ to understand the physical mechanisms underlying the advances shown in $\mathrm{H} 12$ :

(a) TCW-precipitation statistics. Through analysis of 4 years of tropical rainfall and column water vapour satellite measurements, Bretherton et al. (2004) showed that there was a direct, nonlinear relationship between precipitation and the total amount of water in the atmospheric column (TCW). According to their study, the relationship between humidity and rainfall could be an efficient test of a model's ability to simulate deep convection in the Tropics. A similar diagnostic is applied in section 4.1.

(b) Parameters binned based on precipitation. Previous studies have investigated the efficiency of convective moistening in the Tropics by compositing or 
Table 2. Definition of equatorial $\left(10^{\circ} \mathrm{N}-10^{\circ} \mathrm{S}\right)$ regions.

\begin{tabular}{lc}
\hline Abbreviation & Longitude \\
\hline IOW & $60-80^{\circ} \mathrm{E}$ \\
IOE & $80-100^{\circ} \mathrm{E}$ \\
MCW & $90-110^{\circ} \mathrm{E}$ \\
MCE & $110-130^{\circ} \mathrm{E}$ \\
WPW & $120-140^{\circ} \mathrm{E}$ \\
WPE & $140-160^{\circ} \mathrm{E}$ \\
\hline
\end{tabular}

binning parameters, such as relative humidity and temperature, based on precipitation (Thayer-Calder and Randall, 2009; Zhu et al., 2009). The sensitivity of the relationship between precipitation and various parameters to the formulation of $\epsilon_{\mathrm{org}}^{\mathrm{RH}}$, the variable adjustment time-scale $\tau$ and the rate of $\epsilon_{\mathrm{org}}^{\mathrm{RH}}$ are investigated (section 4.2).

(c) Vertical structure of moisture. Since H12 showed that, with the modified convective parametrization, the IFS is able to reproduce a realistic MJO, the April 2009 case study is used to analyse the role of moisture throughout the passage of an MJO (section 4.3).

(d) Temperature and moisture tendencies. The increments in temperature and moisture from the IFS moist physics will be analysed through the passage of the April 2009 MJO case study. The tendencies are calculated by summing contributions from the convection, cloud, radiation and turbulent diffusion schemes (Eqs (1) and (2), section 4.4).

\subsection{Definition of equatorial regions and MJO metric}

The process-based diagnostics described above have been applied to six equatorial areas in the Indo-Pacific region (Table 2). Throughout, the regions will be referred to by the abbreviations in Table 2: Western and Eastern Indian Ocean (IOW and IOE), Maritime Continent (MCW and MCE) and West Pacific (WPW and WPE). To define a metric of MJO activity, 20- to 100-day band-pass filtered OLR from the AVHRR satellite has been averaged over each of the six equatorial regions. Active, suppressed and weak MJO days are defined as days below, above and within one standard deviation of the mean filtered OLR, respectively. Although large increases in intraseasonal variability were observed poleward of $10^{\circ}$ latitude with the modified convective parametrization (H12), the focus here remains on the equatorial Indo-Pacific region of a canonical MJO event.

\section{The role of the mean state}

\subsection{The zonal-mean vertical structure of $T, q$}

The initial analysis will focus on the zonal-mean structures of temperature and specific humidity. Figure 1(a) shows the vertical structure of the zonal-mean temperature at a 5-day forecast lead time from OPER. Recalling Table 1, Figure 1(b) shows that the effect of the modified convective parametrization in $\mathrm{Cy} 32 \mathrm{r} 3$ is a cooling with respect to CONV over the entire depth of the troposphere between $30^{\circ} \mathrm{S}$ and $30^{\circ} \mathrm{N}$, with the exception of a thin layer between 950 and $850 \mathrm{hPa}$. The largest relative cooling, of about $0.6 \mathrm{~K}$, occurs in the tropical upper troposphere between
100 and $200 \mathrm{hPa}$. The Cy32r3 convective parametrization warms the tropical stratosphere between $20^{\circ} \mathrm{S}$ and $20^{\circ} \mathrm{N}$ by up to $0.2 \mathrm{~K}$. The cooling suggests that there is, on average, less convection penetrating into the upper troposphere in the post-Cy32r3 IFS. The magnitude of the temperature anomalies is relatively small, indicative of the homogeneous distribution of temperature in the Tropics. The spatial structure of the difference in zonal-mean temperature in Figure 1(c) suggests that the cooling throughout the tropical troposphere is largely a consequence of the $\epsilon_{\mathrm{org}}^{\mathrm{RH}}$ formulation. In the mid and lower troposphere (upper troposphere), with only the effect of $\epsilon_{\mathrm{org}}^{\mathrm{RH}}$, the cooling signal is reduced (increased) by approximately $0.2 \mathrm{~K}$, compared to the combined effects of $\epsilon_{\mathrm{org}}^{\mathrm{RH}}$ and $\tau$. The mean reduction in active convection shown by the cooling here, combined with the better representation of the MJO (H12), suggest that an effect of $\epsilon_{\mathrm{org}}^{\mathrm{RH}}$ is to prevent the triggering of spurious deep convection. The introduction of the variable $\tau$ in the closure for deep convection is responsible for the remaining tropospheric cooling between 800 and $300 \mathrm{hPa}$. In the upper troposphere $\tau$ had a warming effect with a maximum magnitude above $0.4 \mathrm{~K}$ at $200 \mathrm{hPa}$ (Figure 1(d)). Halving the rate of $\epsilon_{\mathrm{org}}^{R H}$ had the least effect on the vertical structure of zonal-mean temperature at a 5-day forecast lead time: Figure 1(e) shows a slight warming (cooling) in the lower troposphere (mid and upper troposphere) of $0.1-0.2 \mathrm{~K}$.

Differences between the 5-day zonal-mean structure of temperature in the experiments and ERA Interim and YOTC operational analysis, as well as differences between the different analysis products themselves, are all of $\mathrm{O}(0.2 \mathrm{~K})$. However, the uncertainty of tropical temperature in the analysis products is also of $\mathrm{O}(0-0.5 \mathrm{~K})$.

A further effect of the Cy32r3 convective parametrization, or more specifically the $\epsilon_{\mathrm{org}}^{R H}$, is to weaken the subtropical jets by up to $1 \mathrm{~m} \mathrm{~s}^{-1}$ at approximately $100 \mathrm{hPa}$ between $20^{\circ} \mathrm{N}$ and $20^{\circ} \mathrm{S}$, above and equatorward of their maxima (not shown). The vertical structures of zonal wind and temperature are intimately linked through thermal wind balance. Therefore, a dampening of the large-scale circulation pattern is consistent with the mean reduction of active convection penetrating into the tropical upper troposphere shown in Figure 1.

In the Tropics, the vertical structure of the zonal-mean specific humidity (Figure 2) is linked to the vertical structures of temperature and zonal wind through convection. Figure 2(a) shows the zonal-mean specific humidity from OPER at a 5-day forecast lead time. Values of specific humidity decrease with height and distance from the Equator. The largest signal in zonal-mean specific humidity from the Cy32r3 convective parametrization is a tropical midtropospheric moistening, with an equatorial maximum of approximately $0.8 \mathrm{~g} \mathrm{~kg}^{-1}$ between 800 and $700 \mathrm{hPa}$. The cooling in Figure 1 suggested that less active convection was penetrating into the upper troposphere; the moistening at mid levels in Figure 2(b) and (c) suggests that clouds are detraining (and hence moistening their environment) in the mid troposphere. Environmental moisture is crucial in modulating convective activity on the intraseasonal time-scales of the MJO (e.g. Redelsperger et al., 2002; Grabowski, 2003). The aim of the Cy32r3 convective parametrization was to increase the sensitivity of convection in the IFS to environmental moisture (B08), which was suggested by Derbyshire et al. (2004) to be too low. While the Cy32r3 convection 


\section{C. Hirons et al.}

(a)

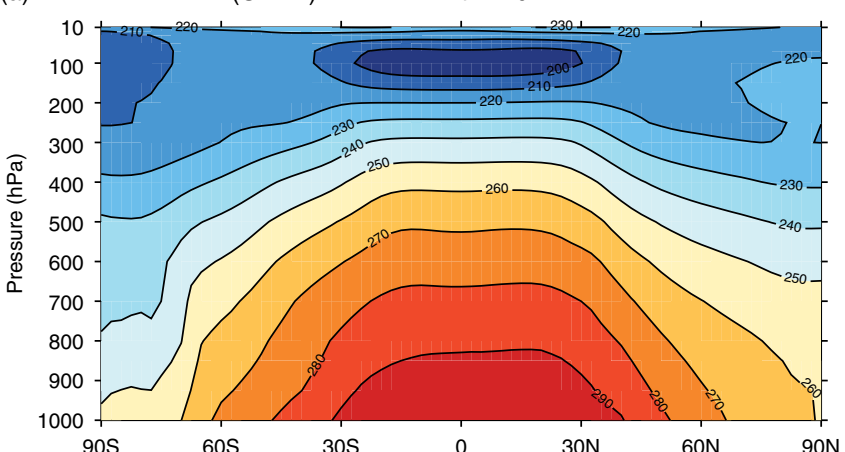

(b)

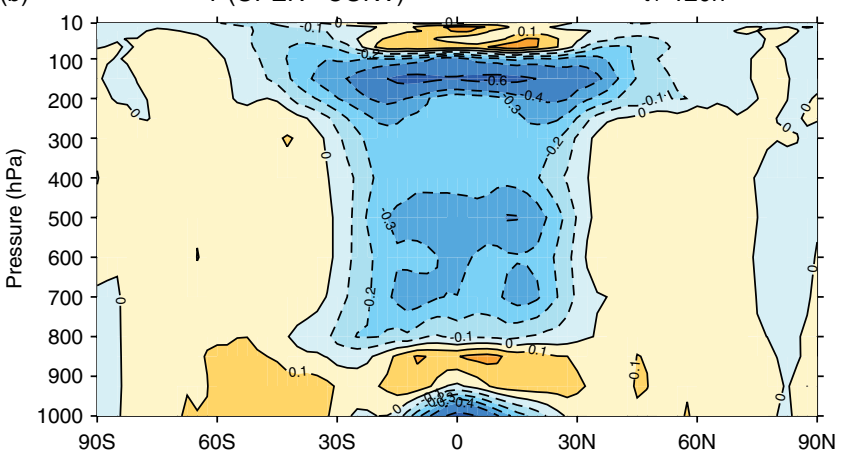

(d) T (OPER - CAPE)

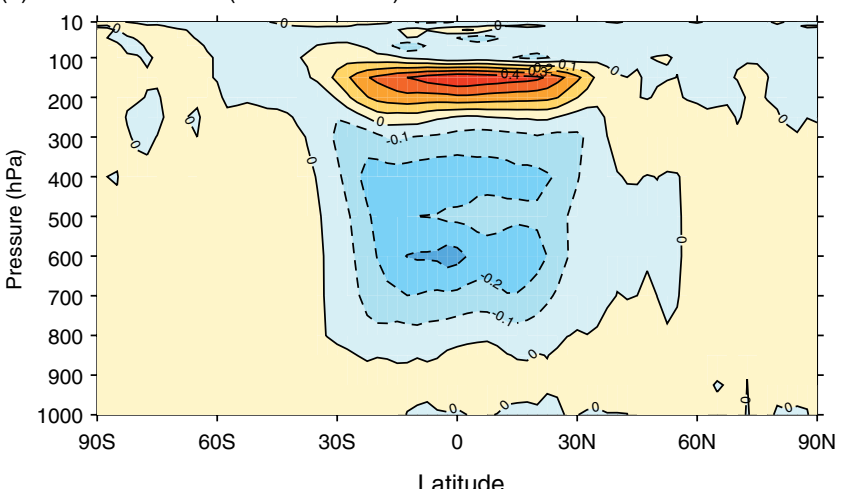

(c)

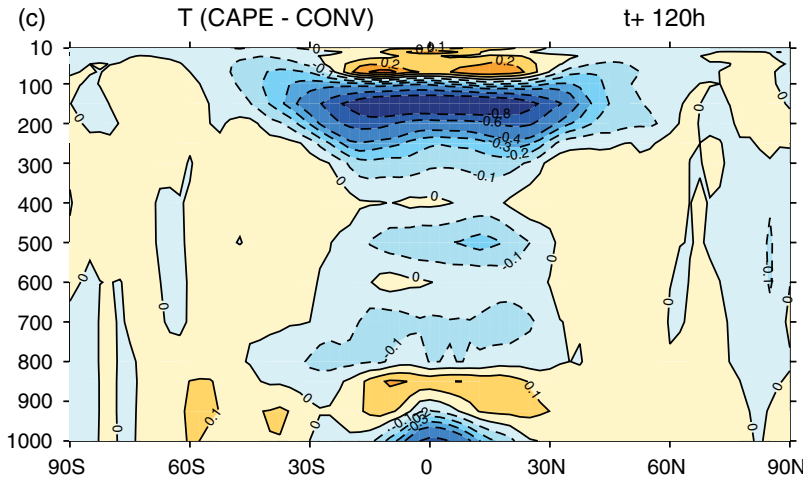

(e)

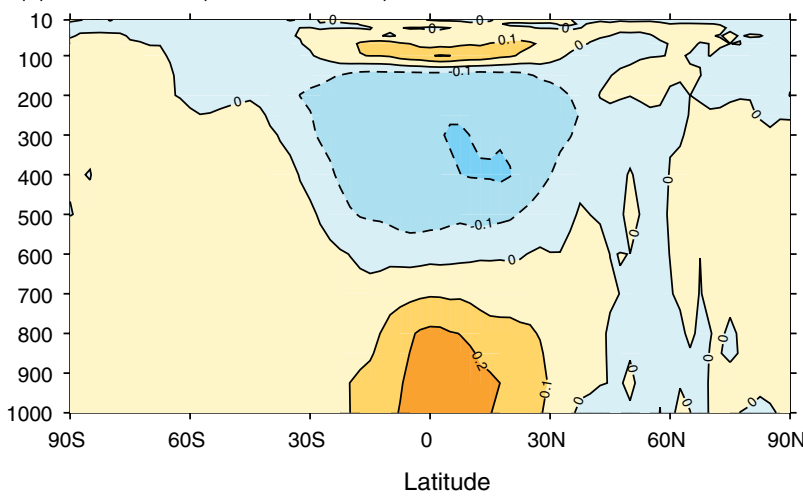

Figure 1. (a) Zonal-mean temperature from OPER at a 5-day forecast lead time. (b) Zonal-mean temperature difference between OPER and CONV (effect of Cy32r3) at a 5-day forecast lead time. (c-e) As (b) but difference between (c) CAPE and CONV (effect of $\epsilon_{\text {org }}^{\mathrm{RH}}$ formulation), (d) OPER and CAPE (effect of $\tau$ ), and (e) OPER and ENTRN (effect of $\epsilon_{\text {org }}^{\mathrm{RH}}$ rate). The zonal mean is calculated for the period from May 2008 to April 2009 over the Indo-Pacific longitudes in Table $2\left(60-160^{\circ} \mathrm{E}\right)$.

scheme clearly moistens the mid troposphere, it is yet unclear whether that is the result or the cause of a more active MJO. The cooling and mid-tropospheric moistening effect of $\epsilon_{\mathrm{org}}^{\mathrm{RH}}$ on the mean state of the IFS is not, however, completely replicated in other studies. Hannah and Maloney (2011) show that increasing the minimum entrainment rate in CAM, which improved the simulation of the MJO, resulted in a tropospheric cooling and drying effect on the mean state.

Additionally, Figure 2(b) shows that at a 5-day forecast lead time the Cy32r3 scheme exhibits an equatorial surface (boundary layer) moistening (drying) of about 0.4 (0.2) $\mathrm{g} \mathrm{kg}^{-1}$. Figure 2(c) shows that $\epsilon_{\mathrm{org}}^{\mathrm{RH}}$ is almost entirely responsible for the vertical structure of zonal-mean moisture observed with the introduction of the Cy32r 3 convective parametrization. With the $\epsilon_{\mathrm{org}}^{\mathrm{RH}}$ formulation alone, the mid-tropospheric (surface) moistening is slightly stronger (weaker), while the drying signal in the boundary layer between 950 and $900 \mathrm{hPa}$ is slightly weakened. The new variable $\tau$ (Figure 2(d)) and the change to the rate of $\epsilon_{\mathrm{org}}^{\mathrm{RH}}$ (Figure 2(e)) have the least impact on the vertical structure of zonal-mean specific humidity; both show weak surface and mid-tropospheric moistening and drying respectively.

Figure 3 shows a comparison of the model drift in zonalmean specific humidity seen in Figure 2, against two analysis products: ERA Interim (ERAI) and the YOTC operational analysis (YOTC). The total column water in both analysis products is almost identical since it is strongly constrained by Special Sensor Microwave Imager (SSMI) measurements. However, it is clear that the tropical specific humidity structure in the analysis is strongly affected by the underlying model (or physics) used to produce it. ERAI does not include the modified convective parametrization, whereas the YOTC operational analysis does. Figure 3(b) and (d) shows that both analysis products exhibit a moister mid troposphere than CONV between 800 and $600 \mathrm{hPa}$, suggesting that, prior to the Cy32r3 convective parametrization, the IFS was too 
(a)

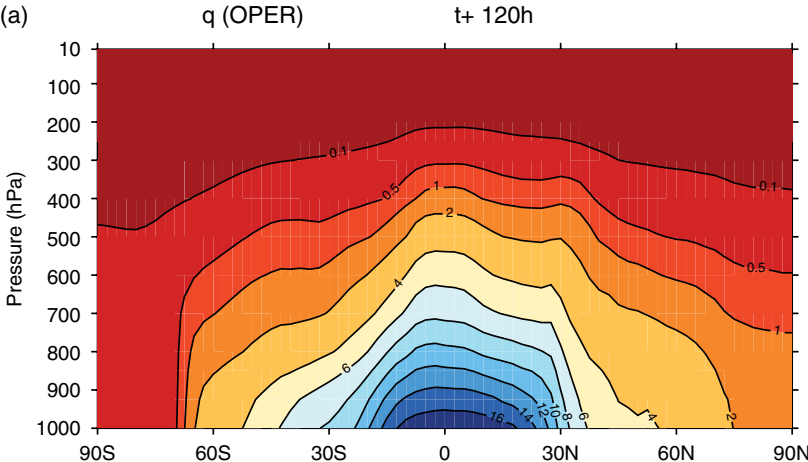

(b)

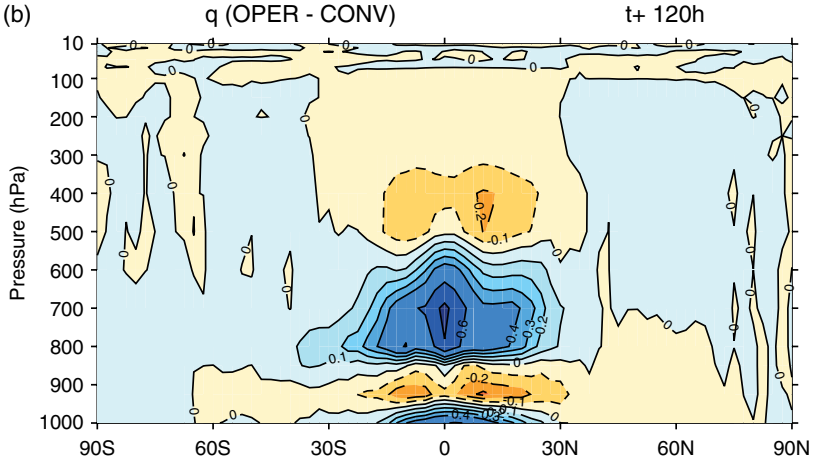

(d)

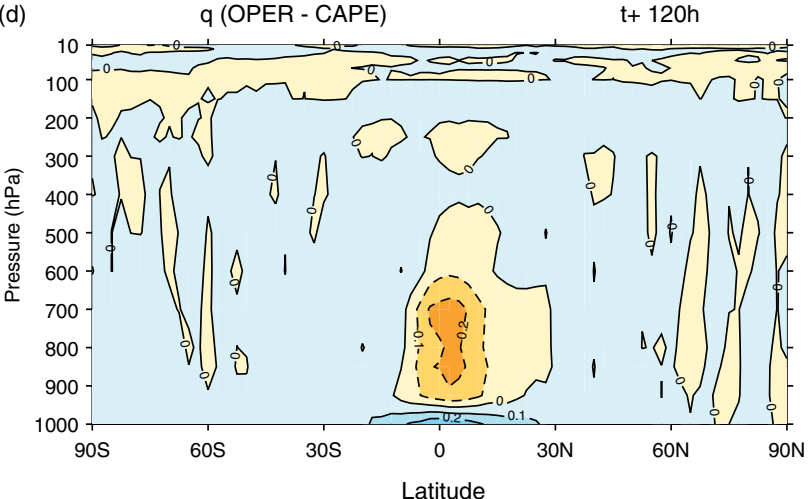

(c)

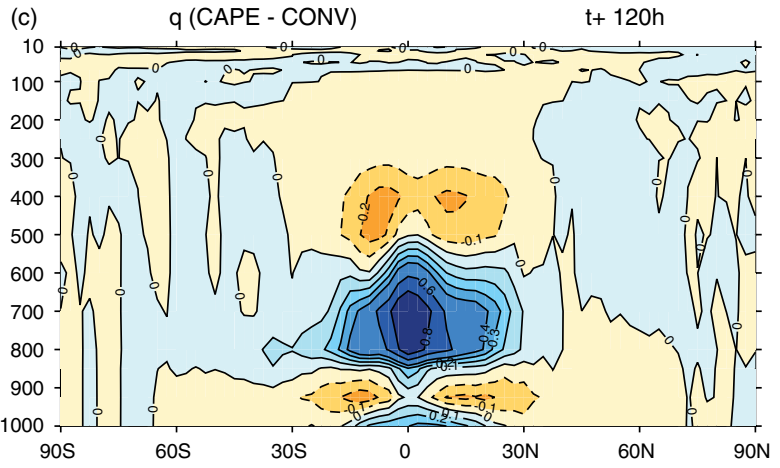

(e) q (OPER - ENTRN)

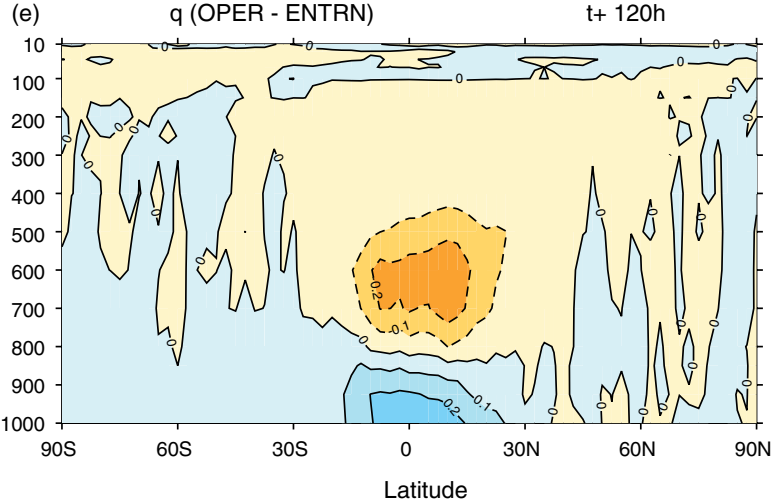

Figure 2. As Figure 1, but for zonal-mean specific humidity.

dry there. In the lower troposphere, however, both analyses are drier than the pre-Cy32r3 IFS. By moistening the mid troposphere and drying the lower troposphere (Figure 2(b)), the effect of the modified convection scheme brings the IFS closer to the YOTC operational analysis (Figure 3(c)); although, at a 5-day forecast lead time, OPER is now too moist by up to $0.3 \mathrm{~g} \mathrm{~kg}^{-1}$ around $600 \mathrm{hPa}$.

\subsection{Distribution of precipitation and cloud}

B08 suggested that the Cy32r3 convective parametrization overestimates precipitation in the Maritime Continent and West Pacific. Here, the distributions of equatorial, $1 \mathrm{~mm} \mathrm{~d}^{-1}$ wide binned precipitation from the IFS are compared with those from the Tropical Rainfall Measuring Mission (TRMM) satellite. The distribution of non-zero precipitation values at a 1-day forecast lead time for the control versions of the IFS and the hindcast experiments are compared to TRMM in Figure 4(a). The contribution of each rain rate bin to the total precipitation is shown in Figure 4(b). Versions of the IFS with a pre-Cy32r3 convection scheme (Cy31r1 and CONV) agree well with TRMM observations at low precipitation rates, but produce too much (not enough) rain at medium (high) precipitation rates of between 3 and $23 \mathrm{~mm} \mathrm{~d}^{-1}$ (above $23 \mathrm{~mm} \mathrm{~d}^{-1}$ ). Additionally, Cy31r1 and CONV exhibit a preferred, but unrealistic, precipitation rate of approximately $10 \mathrm{~mm} \mathrm{~d}^{-1}$ (Figure 4(b)). This behaviour has also been seen in the UKMO UM* (Holloway, 2011) and NCAR CAM3.0 $0^{\dagger}$ (Thayer-Calder and Randall, 2009).

Comparing OPER and CONV shows that the introduction of the Cy32r3 convection scheme increased the amount of precipitation at low and high rain rates and decreased precipitation at medium rain rates. The modified formulation of convection results in a distribution of precipitation that no longer exhibits a preferred precipitation rate of $10 \mathrm{~mm} \mathrm{~d}^{-1}$ and, therefore, shows closer agreement with TRMM observations at medium and high rain rates. Since OPER, CAPE and ENTRN all contain the $\epsilon_{\text {org }}^{\mathrm{RH}}$ formulation and all exhibit similar distributions of precipitation, the differences attributed to the $\mathrm{Cy} 32 \mathrm{r} 3$ convective parametrization

*The Unified Model from the Met Office, UK

†Community Atmosphere Model version 3.0 from the National Center of Atmospheric Research, USA. 


\section{C. Hirons et al.}

(a)

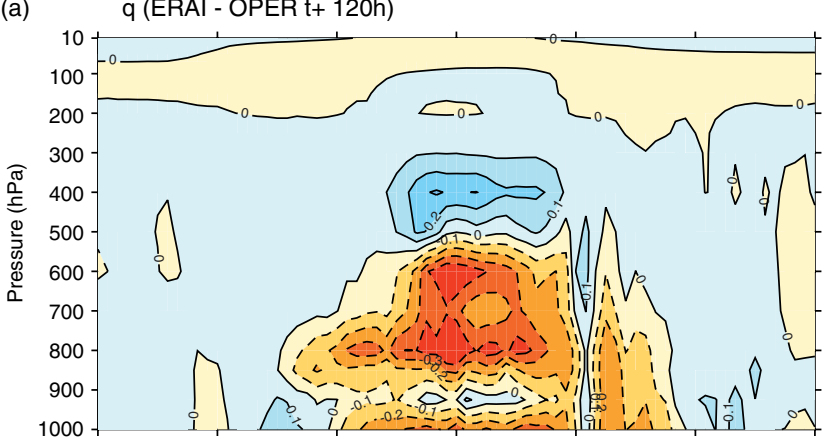

(c)

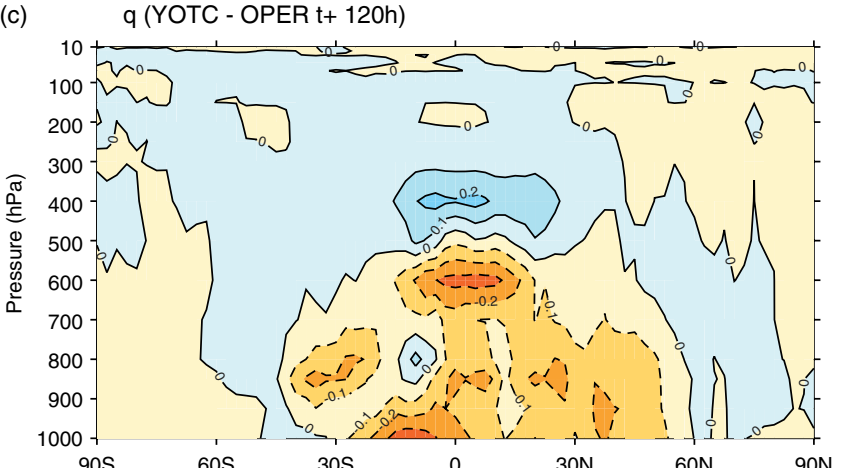

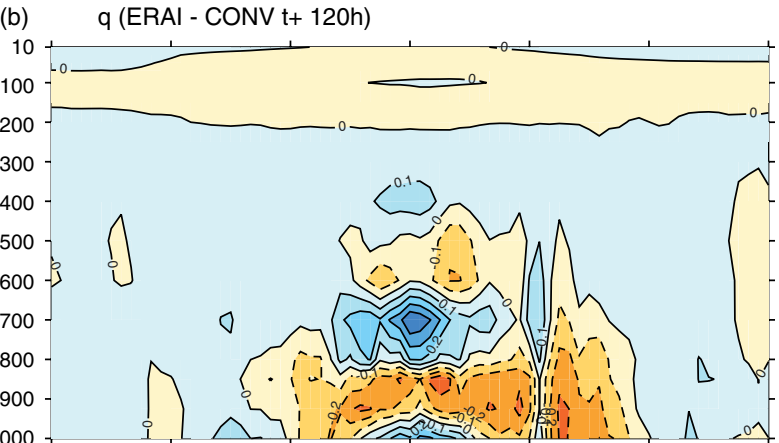

(d) $\quad \mathrm{q}($ YOTC - CONV t+ 120h)

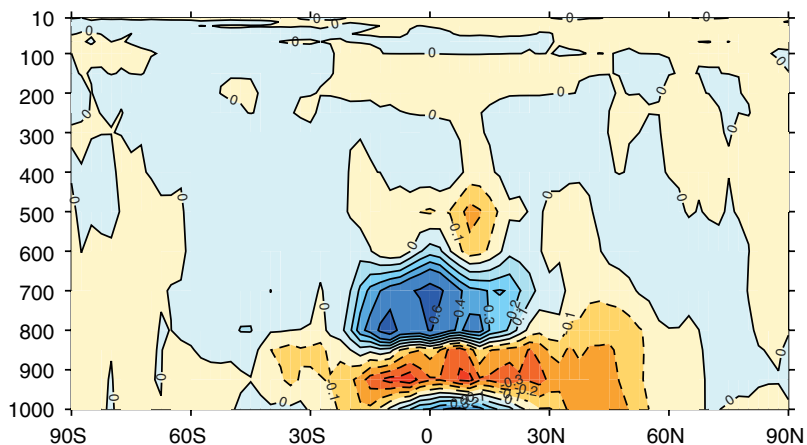

Figure 3. (a, b) Zonal-mean specific humidity difference between ERA Interim (ERAI) and OPER and CONV at a 5-day forecast lead time respectively. (c, d) Zonal-mean difference between YOTC operational analysis (YOTC) and OPER and CONV respectively. Zonal-mean calculated as in Figures 1 and 2 for the Indo-Pacific region.
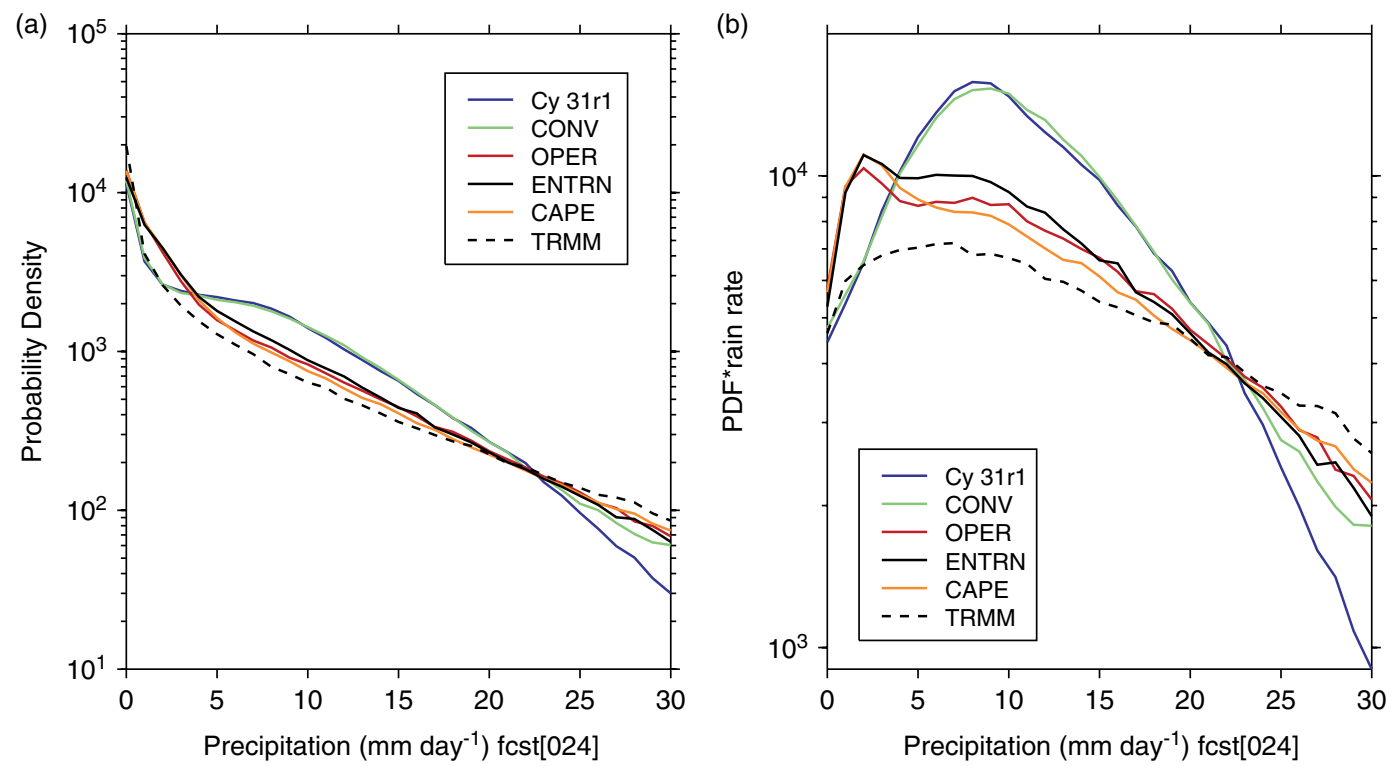

Figure 4. (a) Probability density function (PDF) for non-zero values of precipitation at a 1-day forecast lead time in $\mathrm{mm}^{-1}$ from $\mathrm{TRMM}^{\mathrm{observations}}$ (dashed line), Cy31r1 (blue line), CONV (green line), OPER (red line), ENTRN (black line) and CAPE (orange line). The PDF is calculated from $1 \mathrm{~mm} \mathrm{~d}^{-1}$ wide bins of precipitation in the equatorial belt between $10^{\circ} \mathrm{N}$ and $10^{\circ} \mathrm{S}$. (b) As (a), but the contribution to the total precipitation by each rain rate.

can be more directly attributed to $\epsilon_{\mathrm{org}}^{\mathrm{RH}}$. However, in OPER, CAPE and ENTRN there is still not enough heavy rain and too much light rain, with an unrealistic peak at approximately $2 \mathrm{~mm} \mathrm{~d}^{-1}$ (Figure $4(\mathrm{~b})$ ), a feature in common with simulations from the NCAR SP-CAM3 (Thayer-Calder and Randall, 2009). All versions of the IFS underestimate the number of dry days compared with TRMM, which, using data from CAM3.0 and SP-CAM, Thayer-Calder and Randall (2009) suggest could contribute to the unrealistic peaks in rainfall at 10 and $2 \mathrm{~mm} \mathrm{~d}^{-1}$, respectively.
To investigate the effect of the modified mean state on clouds, the zonal-mean vertical structure of cloud cover is examined. There are three prominent modes of convection in the Tropics: shallow convection, cumulus congestus and deep precipitating convection (Johnson et al., 1999). Shallow convection detrains at the height of the boundary layer inversion; deep convection penetrates into the upper troposphere, usually detraining at the tropopause. Cumulus congestus penetrates to a thin stable layer at the zero-degree isotherm, which, in the Tropics, is at 
(a)

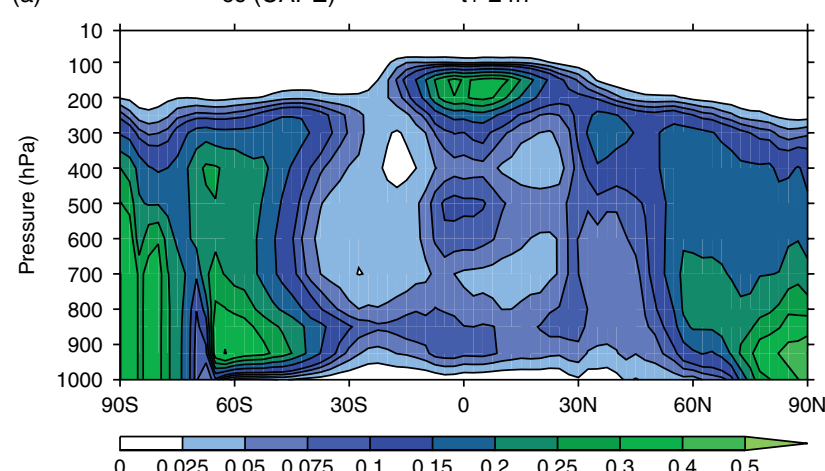

(b)

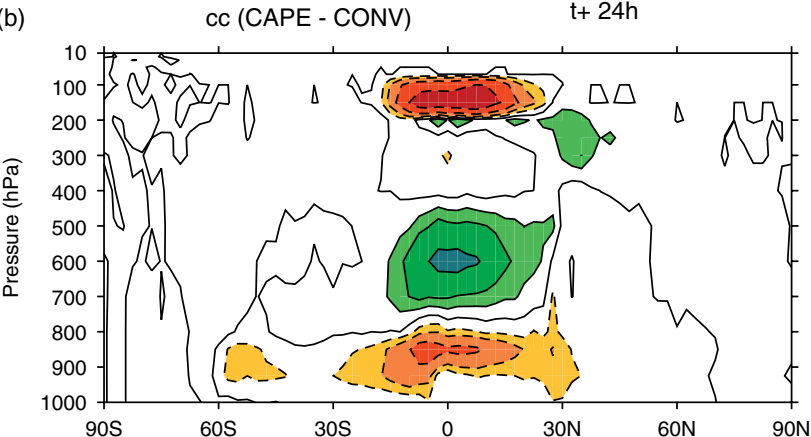

(c)

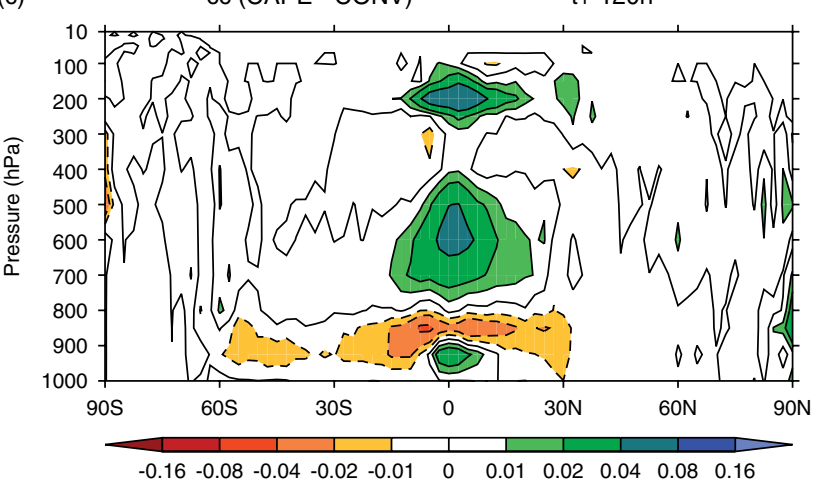

Figure 5. (a) Zonal-mean cloud fraction from CAPE at a 1-day forecast lead time (b) and (c) zonal-mean cloud fraction difference between CAPE and CONV (effect of $\epsilon_{\mathrm{org}}^{\mathrm{RH}}$ ) at a 1-day and 5-day forecast lead time respectively. The zonal mean is calculated for the period from May 2008 to April 2009 over the Indo-Pacific longitudes in Table $2\left(60-160^{\circ} \mathrm{E}\right)$.

approximately $500 \mathrm{hPa}$. The layer is maintained by the heat absorbed by the melting of precipitation from ice to liquid phase.

Figure 5(a) shows the Indo-Pacific zonal-mean vertical structure of cloud cover from CAPE at a 1-day forecast lead time. The trimodal distribution of tropical cloud described above is apparent, with maxima above the boundary layer, at the melting layer (approximately $500 \mathrm{hPa}$ ) and at the tropopause (approximately $100 \mathrm{hPa}$ ). Figure 5(b) and (c) shows the difference in zonal-mean cloud cover between CAPE and CONV, which highlight the effects of $\epsilon_{\mathrm{org}}^{\mathrm{RH}}$, at a 1-day and 5-day forecast lead time, respectively. The main differences occur in the Tropics. At a 1-day forecast lead time, with the introduction $\epsilon_{\mathrm{org}}^{\mathrm{RH}}$, there is an increase in cumulus congestus cloud in the mid troposphere and a decrease in the amount of shallow and deep convection in the lower and upper troposphere (Figure 5(b)). The increase in cumulus congestus with the $\epsilon_{\mathrm{org}}^{\mathrm{RH}}$ formulation results in an increase in both cloud liquid- and ice-water content between 500 and $800 \mathrm{hPa}$ and 400 and $600 \mathrm{hPa}$, respectively (not shown). As forecast lead time increases, the effect of $\epsilon_{\mathrm{org}}^{\mathrm{RH}}$ is to increase upper-tropospheric cloud as well as cumulus congestus (Figure 5(c)).

The role of deep and shallow convection has long been established, but the importance of cumulus congestus in the transition from shallow to deep convection has been recognized only more recently (e.g. Johnson et al., 1999; Waite and Khouider 2010). In a dry environment, the entrainment of dry air into a convective plume will dilute the plume, reducing the cloud buoyancy and inhibiting the development of deep convection, resulting in a lower cloud-top level (CTL).

The $\epsilon_{\mathrm{org}}^{\mathrm{RH}}$ formulation is designed to entrain more in a dry column, which will enhance the process described above. This explains why more clouds are detraining in the mid troposphere, and increasing the cloud cover (and liquid- and ice-water content) there (Figure 5). The mid-tropospheric moistening from the detrainment of congestus clouds results in conditions which are more favourable for deep convection. When a convective plume encounters high humidity in the mid troposphere, moister air is entrained, which limits the decreasing of the cloud buoyancy and results in the development of deeper convection. The importance of the transition from shallow to deep convection in the Tropics is discussed further in section 4 .

\subsection{Contribution from the physics tendencies}

The $\epsilon_{\mathrm{org}}^{\mathrm{RH}}$ formulation modified the vertical structure of temperature, zonal wind and specific humidity in the IFS (section 3.1). Here, through analysis of the heating and moisture tendencies, the contribution from individual components of the IFS to the modified vertical structures shown in section 3.1 can be identified. Figures 6 and 7 show the vertical structure of the zonal-mean increments in temperature and specific humidity from the dynamics, convective parametrization and-by removing the effect of the shallow convection scheme-the contribution from deep convection only. The operational YOTC archive (OPER) only contains tendencies until a $36 \mathrm{~h}$ forecast lead time; therefore, where necessary and for the longer lead times, CAPE is used as a proxy for OPER. The domain has been limited to tropical latitudes $\left(30^{\circ} \mathrm{N}-30^{\circ} \mathrm{S}\right)$, where the effect of the modified $\epsilon_{\mathrm{org}}^{\mathrm{RH}}$ formulation on the mean state of the IFS was largest (section 3.1).

Figure 1(c) showed that the main effect of $\epsilon_{\mathrm{org}}^{\mathrm{RH}}$ on the zonal-mean temperature was to cool the tropical troposphere, especially at upper levels. Figure 6(a) shows that the dynamics are not responsible for any of that cooling; in fact, there is a slight warming at upper levels. Over the first 5 days of the forecast, the convective parametrization has cooled the tropical upper and lower troposphere and boundary layer by up to 2, 2.5 and $8 \mathrm{~K}$, respectively (Figure $6(\mathrm{~b})$ ). In addition, there is a distinct warming of the mid troposphere by up to $3 \mathrm{~K}$ after 5 days. Comparing Figure 6(b) and (c) reveals that the deep convective parametrization is largely responsible for the vertical structure of increments in temperature, exhibiting a strong cooling at the surface, warming in the mid troposphere and further cooling aloft. Although the vertical structure is the same, this comparison also reveals 
(a)

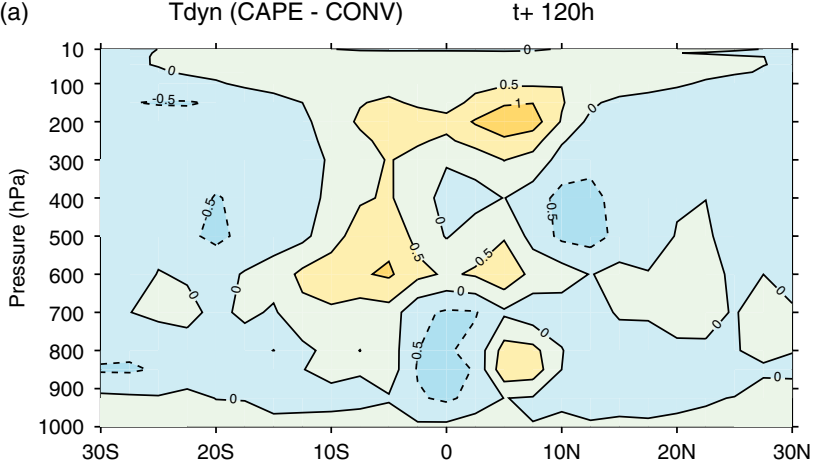

(b)

(b) Tconv (CAPE - CONV) t+120h

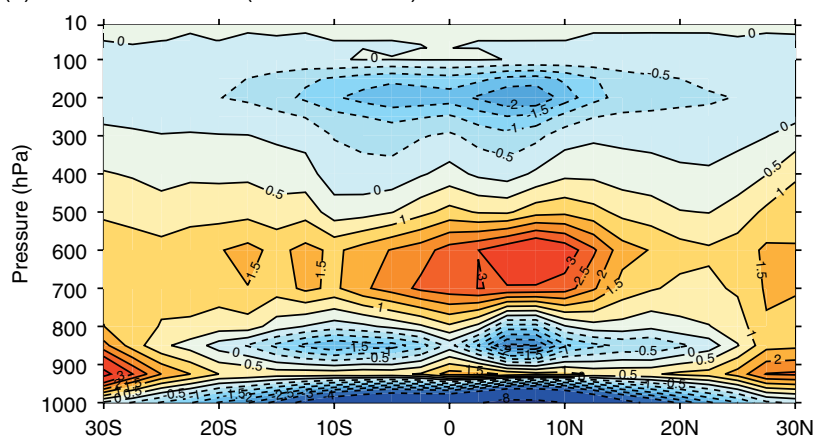

(c) Tdeep (CAPE - CONV) $\quad t+120 \mathrm{~h}$

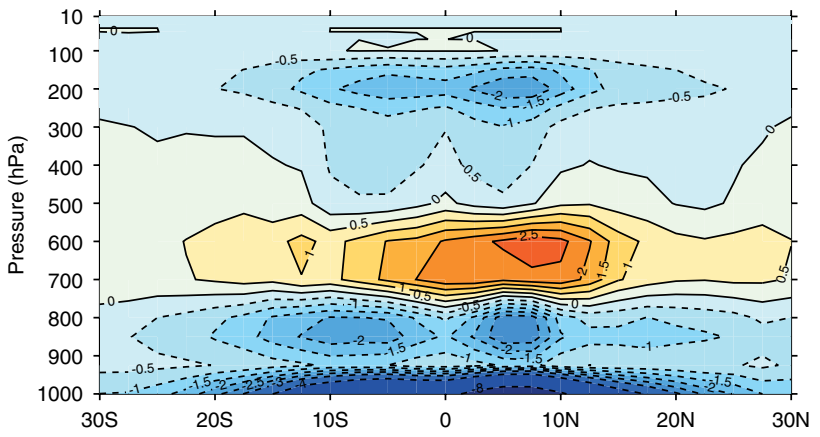

Figure 6. Zonal-mean temperature increment (K) from (a) dynamics, (b) convection scheme and (c) the contribution from deep convection accumulated after 5 days of the forecast. The zonal mean is calculated for the period from May 2008 to April 2009. Negative values are shown by dashed contours.

that the deep convective parametrization is only partly responsible for the mid-tropospheric warming; Figure 6(b) shows that the shallow convection scheme is responsible for the remaining warming in that layer. While Figure 6(c) suggests that some aspects of the modified vertical structure of the zonal-mean temperature are a direct result of $\epsilon_{\mathrm{org}}^{\mathrm{RH}}$ in the formulation for deep convection. However, in spite of a stronger convective mid-tropospheric heating with respect to CONV, CAPE and OPER have a colder mid troposphere (Figure 1). This can be explained by the cloud and radiation schemes which, combined, account for in excess of $4 \mathrm{~K}$ cooling in the mid troposphere between 700 and $600 \mathrm{hPa}$ (not shown).

In contrast, the convective parametrization, or indeed the deep convection scheme, had little direct effect on the increments in zonal wind over the first 5 days of the forecast (not shown). This confirms that the observed reduction in the strength of the subtropical jets is the dynamical response to the cooling at upper levels caused by the deep convection scheme (Figure 6(c)). (a)

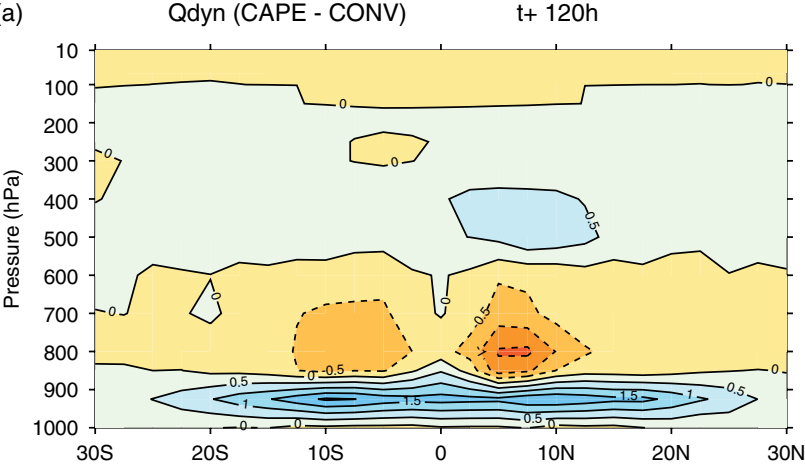

(b)

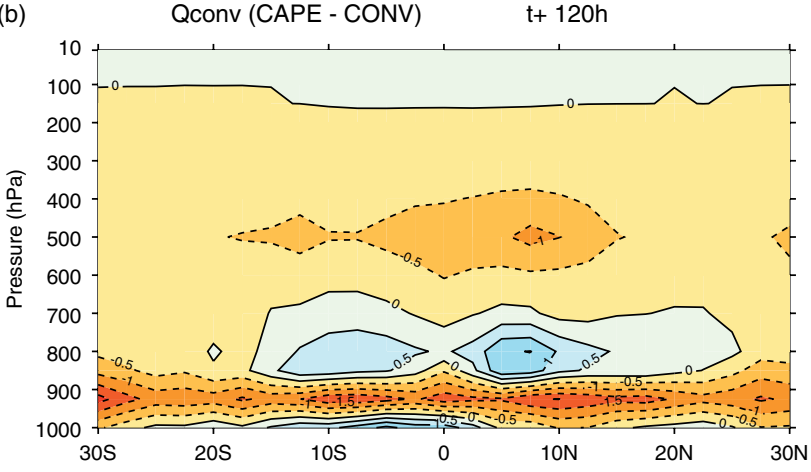

(c)

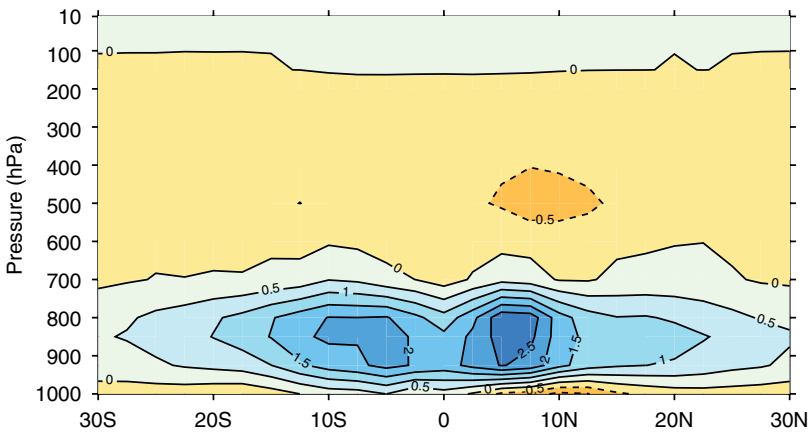

Figure 7. As Figure 6, but for zonal mean specific humidity increments $\left(\mathrm{g} \mathrm{kg}^{-1}\right)$.

Figure 2(c) showed that the effect of the modified $\epsilon_{\mathrm{org}}^{\mathrm{RH}}$ formulation was to moisten the mid troposphere between 600 and $800 \mathrm{hPa}$. Figure 7(a) shows that while the effect of the moisture increments from the dynamics is to moisten the boundary layer and lower troposphere by up to $2 \mathrm{~g} \mathrm{~kg}^{-1}$, in the mid troposphere their effect is a drying of up to $1.5 \mathrm{~g} \mathrm{~kg}^{-1}$ after 5 days of the forecast. The contribution of the convection scheme to the increment in humidity is of the opposite sign to the dynamics: in the lower troposphere there is a consistent drying across the entire equatorial belt of up to $2 \mathrm{~g} \mathrm{~kg}^{-1}$, with a maximum around $900 \mathrm{hPa}$ (Figure 7(b)). Comparison with Figure 7(c) shows that the shallow convection scheme is responsible for all the convective drying near the surface. Above the dry layer, Figure 7(b) exhibits convective moistening of over $1 \mathrm{~g} \mathrm{~kg}^{-1}$ near the Equator. The deep convection scheme moistens the lower troposphere with respect to CONV from the surface up to $750 \mathrm{hPa}$, with a maximum of approximately $2.5 \mathrm{~g} \mathrm{~kg}^{-1}$ north of the Equator between 800 and $950 \mathrm{hPa}$. Figure 7(a) confirms that the mid-tropospheric moistening is not a result of the dynamics. There is a further moistening of over $1 \mathrm{~g} \mathrm{~kg}^{-1}$ between 650 and $800 \mathrm{hPa}$ from the cloud 

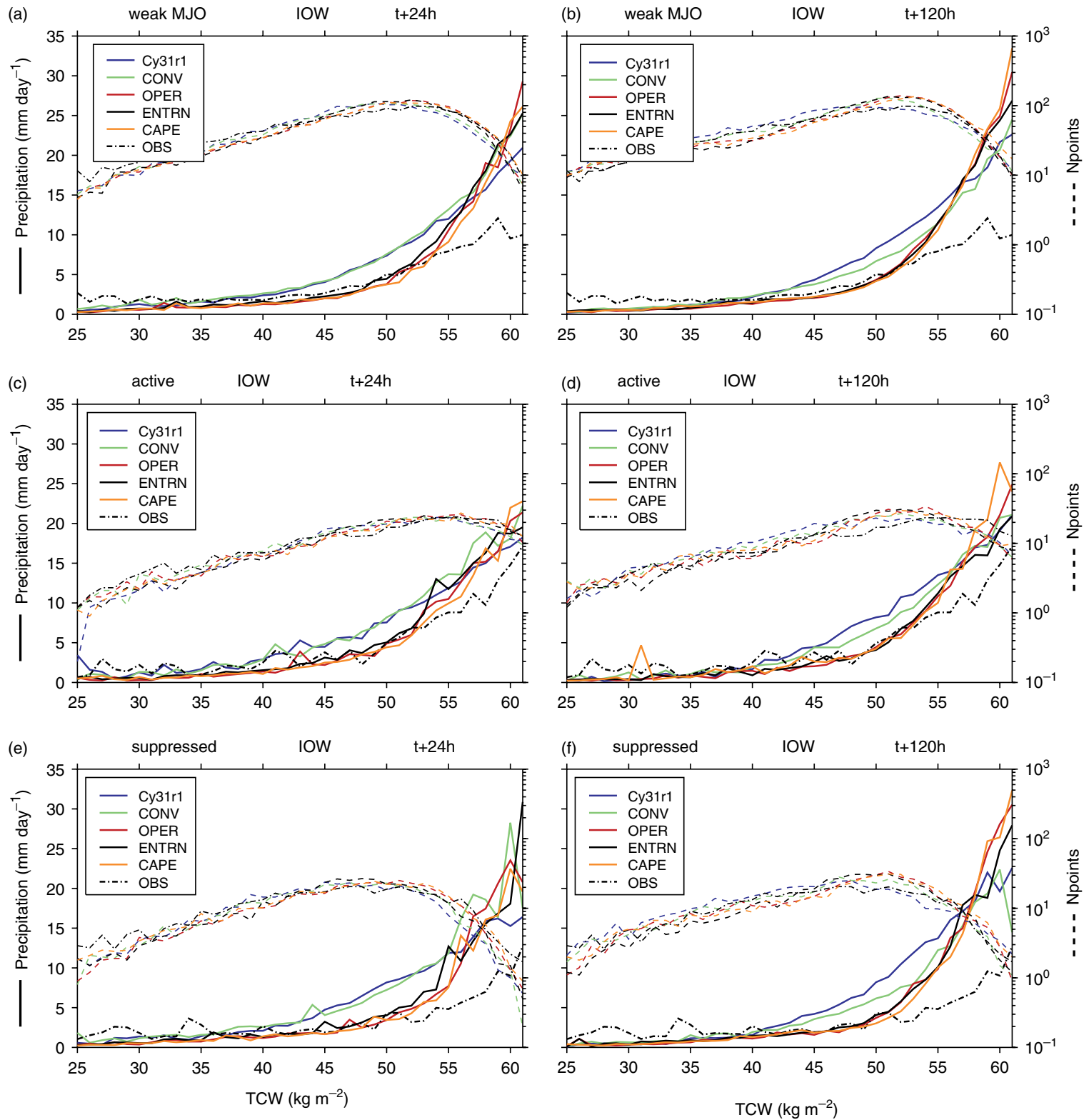

Figure 8. Solid lines represent daily averaged precipitation in $1 \mathrm{~kg} \mathrm{~m}^{-2}$ wide bins of total column water (TCW) for grid points in IOW at a 1 -day (left) and 5-day (right) forecast lead time for weak MJO (a, b), active (c, d) and suppressed days (e, f). Distribution of data points in each bin is represented by the dashed lines. Observations (dash-dot) refers to precipitation from TRMM satellite data and TCW from ECMWF operational analysis.

scheme (not shown). This moistening derives mainly from the convective detrainment term of cloud condensate from shallow and congestus convection which, by construction, couples the convection and cloud schemes. Therefore, although it appears as a cloud tendency, it is intimately linked to the formulation of convection in the IFS. For this reason, it can be concluded that the mid-tropospheric moistening in the Tropics, which is observed in Figure 2, can be explained by the convection and cloud schemes in the IFS model physics.

\section{The application of process-based diagnostics}

\subsection{TCW: precipitation statistics}

In the Tropics, sustained deep convection has long been associated with a humid environment (e.g. Raymond, 2000; Derbyshire et al., 2004). However, the relationship between the total column precipitable water (TCW) and precipitation has only emerged more recently as being important to the simulation of intraseasonal phenomena such as the MJO (Bretherton et al., 2004). To investigate this relationship in each of the equatorial regions in Table 2, the daily accumulated precipitation is binned into $1 \mathrm{~kg} \mathrm{~m}^{-2}$ wide bins of TCW and divided into weak, active and suppressed MJO days according to the MJO metric described in section 2.4. In all versions of the IFS, across all regions, precipitation values increase rapidly with increasing TCW; results for IOW (Figure 8) are shown as a representative sample of the Indo-Pacific region. The observed relationship between precipitation and TCW, plotted as the dash-dot line, is defined using TRMM satellite precipitation and ECMWF operational analysis TCW.

In Figure 8, for quantities of TCW above $40 \mathrm{~kg} \mathrm{~m}^{-2}$, there is a clear distinction between the behaviour of precipitation at different values of TCW in the versions of the IFS with $\epsilon_{\mathrm{org}}^{\mathrm{RH}}$ (OPER, ENTRN and CAPE) and those with $\epsilon_{\mathrm{org}}^{\mathrm{MC}}(\mathrm{Cy} 31 \mathrm{r} 1$ and CONV). This distinction is consistent at longer forecast 
lead times (Figure 8(b), (d) and (f)) and for all types of days; active and suppressed days exhibit a noisier distribution, but this is due to fewer days in the TCW bins compared with weak MJO days (dashed lines). For TCW amounts between 40 and $55 \mathrm{~kg} \mathrm{~m}^{-2}$, versions of the IFS with $\epsilon_{\text {org }}^{\mathrm{RH}}$ agree well with observations, exhibiting a lower precipitation rate at the same quantities of TCW than versions of the IFS with $\epsilon_{\mathrm{org}}^{\mathrm{MC}}$. At higher values of TCW, above $55 \mathrm{~kg} \mathrm{~m}^{-2}$, precipitation rates in OPER, ENTRN and CAPE all increase sharply. At these values, versions of the IFS with $\epsilon_{\mathrm{org}}^{\mathrm{RH}}$ precipitate more than those with $\epsilon_{\mathrm{org}}^{\mathrm{MC}}$; all versions of the IFS produce more precipitation than that observed by satellite. The rapid increase in precipitation at higher TCW contents in the IFS is more apparent during suppressed days than active MJO days, especially at longer forecast lead times (Figure 8(f)). Furthermore, since OPER and CAPE behave similarly in Figure 8 , it can be concluded that the modified variable adjustment time-scale $\tau$ had little effect on the relationship between TCW and precipitation. The relationship described above between TCW and precipitation in IOW is also true of IOE, WPE and MCW (not shown).

The relationship does not hold, however, in MCE or WPW (not shown) where the main differences between the versions of the IFS are at low values of TCW. At a 1-day forecast lead time all versions of the IFS, with the exception of Cy31r1, display a small peak in precipitation rates between 25 and $37 \mathrm{~kg} \mathrm{~m}^{-2}$, followed by a rapid decrease between 37 and $40 \mathrm{~kg} \mathrm{~m}^{-2}$. The same feature is reproduced in the observations. The formulation of $\epsilon_{\mathrm{org}}^{\mathrm{RH}}$ is not responsible for this peak; both OPER and CONV display the same behaviour despite having different entrainment formulations: $\epsilon_{\text {org }}^{\mathrm{RH}}$ and $\epsilon_{\mathrm{org}}^{\mathrm{MC}}$ respectively. Since Cy31r1 is the only version of the IFS run at a lower horizontal resolution, $T_{\mathrm{L}} 255(\sim 80 \mathrm{~km})$ compared with $T_{\mathrm{L}} 799(\sim 25 \mathrm{~km})$, capturing this observed feature could be a consequence of the islands of the Maritime Continent being represented more accurately. This could also be related to orographic enhancement of precipitation or the strength of the land-sea breeze around the islands.

The 'best' MJO was produced with $\epsilon_{\mathrm{org}}^{\mathrm{RH}}(\mathrm{H} 12)$, and an effect of $\epsilon_{\mathrm{org}}^{\mathrm{RH}}$ was to moisten the tropical mid troposphere between 800 and $500 \mathrm{hPa}$ (section 3.1). Therefore, the TCW precipitation diagnostic has been repeated for mid-level specific humidity-averaged between 800 and $500 \mathrm{hPa}$-to identify whether the relationship between precipitation and environmental humidity at those levels has changed with the introduction of $\epsilon_{\mathrm{org}}^{\mathrm{RH}}$. For brevity, only IOW is shown (Figure 9). As with the TCW precipitation diagnostic, comparisons are made with observations (dash-dot line), using TRMM precipitation and ECMWF operational analysis specific humidity.

In all versions of the IFS, across all equatorial regions, precipitation rates increase with increasing mid-level humidity. As with TCW and precipitation, there is a distinction between versions of the IFS with $\epsilon_{\mathrm{org}}^{\mathrm{RH}}$ and versions with $\epsilon_{\mathrm{org}}^{\mathrm{MC}}$, but only above approximately $2.4 \mathrm{~g} \mathrm{~kg}^{-1}$. At low precipitation rates and dry mid-tropospheric humidity values, all versions of the IFS exhibit similar behaviour: in IOW and WPE, the model underestimates the amount of precipitation compared with observations, especially during weak MJO days (e.g. Figures 9(a) and (b)). This is not a characteristic observed in other equatorial regions (not shown).
Between 2.4 and $4.8 \mathrm{~g} \mathrm{~kg}^{-1}$, where precipitation rates increase gradually with increasing humidity, for a given amount of humidity at mid levels, versions of the IFS with $\epsilon_{\mathrm{org}}^{\mathrm{RH}}$ are able to maintain a lower precipitation rate than those with $\epsilon_{\mathrm{org}}^{\mathrm{MC}}$. In the equatorial regions which are predominantly made up of ocean, IOW (Figure 9), IOE and WPE (not shown), this results in a closer agreement with observations between 2.4 and $4.8 \mathrm{~g} \mathrm{~kg}^{-1}$. Conversely, in the equatorial regions containing the Indonesian islands, MCW, MCE and WPW (not shown), maintaining a lower precipitation rate for a given mid-tropospheric humidity leads to a less realistic relationship compared with observations. These results suggest that, with $\epsilon_{\mathrm{org}}^{\mathrm{RH}}$, the IFS is able to build up more moisture in the atmospheric column before it is removed by convective precipitation. The increase of entrainment in dry columns could be the mechanism through which convection is suppressed and the build-up of humidity is achieved.

Above $4.8 \mathrm{~g} \mathrm{~kg}^{-1}$, precipitation rates in $\epsilon_{\mathrm{org}}^{\mathrm{RH}}$ versions of the IFS increase more rapidly than those versions with $\epsilon_{\mathrm{org}}^{\mathrm{MC}}$, resulting in all versions of the IFS behaving similarly when the mid troposphere is very moist. However, compared with observations, all versions of the IFS overestimate the amount of precipitation, a characteristic true of all equatorial regions for all types of days. Comparing OPER and CAPE in Figure 9 shows that, as with the TCW precipitation statistics, the variable adjustment time-scale $\tau$ does not substantially affect the relationship between moisture in the mid troposphere and precipitation rates.

\subsection{Parameters binned based on precipitation}

Figure 4 revealed that IFS versions with $\epsilon_{\mathrm{org}}^{\mathrm{MC}}$ exhibited an unrealistic preferred rainfall rate of approximately $10 \mathrm{~mm} \mathrm{~d}^{-1}$, while versions with $\epsilon_{\text {org }}^{\mathrm{RH}}$ had a distribution that, although overestimating precipitation at low rainfall rates, agreed more closely with TRMM. The aim of the analysis carried out here is to further investigate the relationship between rainfall rate and TCW. Figure 10(a) shows the observed two-dimensional histogram of TCW versus precipitation from ERA-Interim and TRMM satellite data respectively calculated for days between May 2008 and April 2009, and averaged over the IOW region; Figure 10(b) shows the equivalent from OPER at a 1-day forecast lead time. Only IOW at a 1-day forecast lead time is shown; consistent behaviour was found for the remaining five equatorial regions and for longer forecast lead times.

In both model and observations, the maximum in the percentage of days occurs at low values of precipitation (up to $1 \mathrm{~mm} \mathrm{~d}^{-1}$ ) and relatively high values of TCW $\left(44-56 \mathrm{~kg} \mathrm{~m}^{-2}\right.$ ) (Figure 10(a) and (b)). Figure 10(c)-(f) compares OPER and CONV, CAPE and CONV, OPER and CAPE, and OPER and ENTRN, revealing the effect of the Cy32r3 convective parametrization, $\epsilon_{\mathrm{org}}^{\mathrm{RH}}$ formulation, $\tau$ and $\epsilon_{\mathrm{org}}^{\mathrm{RH}}$ rate, respectively. Consistent with the analysis in section 4.1, Figure 10(d) shows that in a moist column with $\epsilon_{\mathrm{org}}^{\mathrm{RH}}$ the IFS produces less rain than with $\epsilon_{\mathrm{org}}^{\mathrm{MC}}$. For example, for a value of TCW of approximately $50 \mathrm{~kg} \mathrm{~m}^{-2}$ with $\epsilon_{\mathrm{org}}^{\mathrm{RH}}$ the IFS produces more days with precipitation of up to $3 \mathrm{~mm} \mathrm{~d}^{-1}$ and fewer days with precipitation at values above $4 \mathrm{~mm} \mathrm{~d}^{-1}$. Reducing the rate of $\epsilon_{\mathrm{org}}^{\mathrm{RH}}$ has the equivalent change in behaviour but it is somewhat weakened (Figure 10(f)). The effect of the variable $\tau$ is weak and has the opposite sign; in 

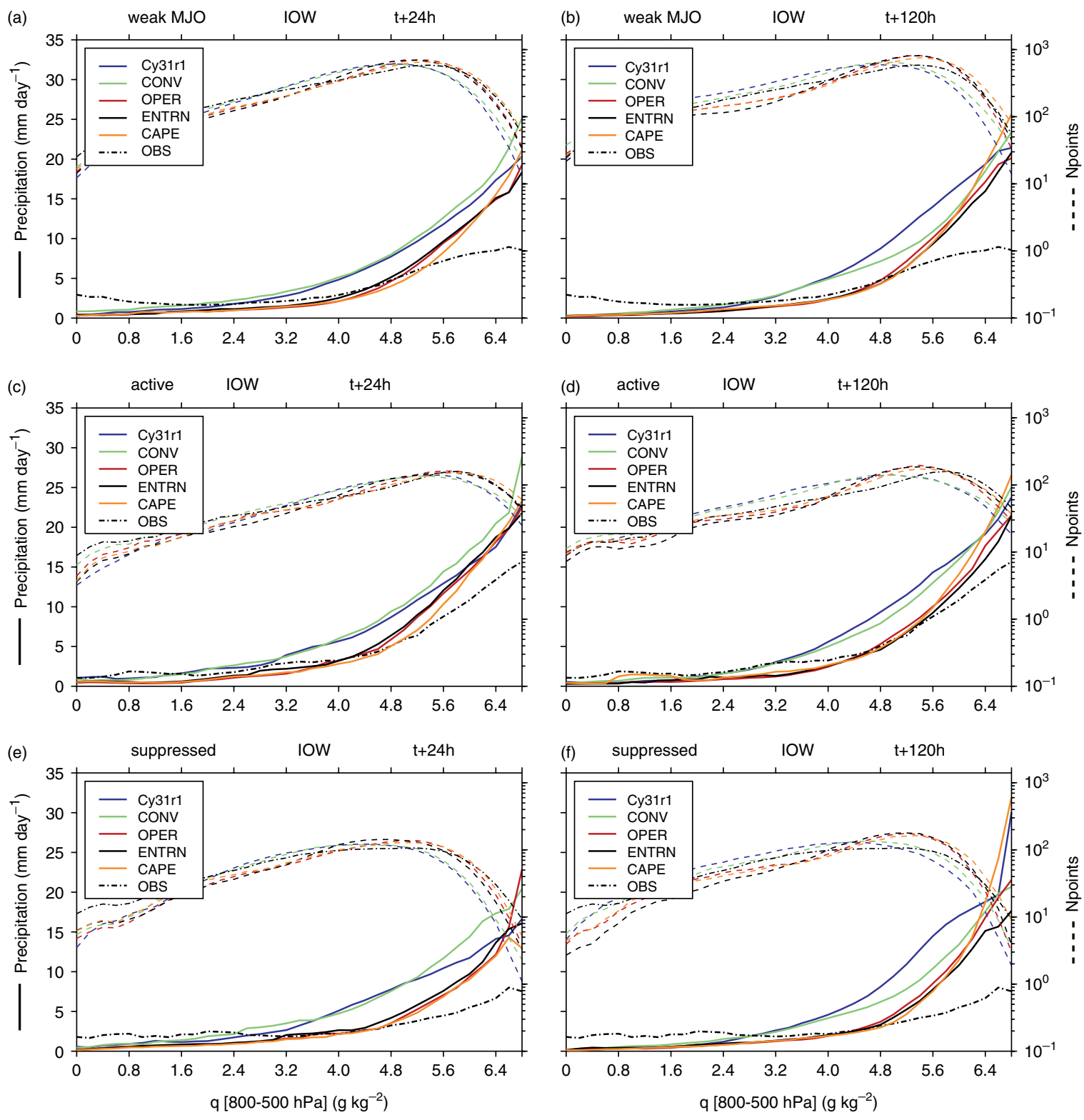

Figure 9. As Figure 8, but for daily averaged precipitation in $0.2 \mathrm{~g} \mathrm{~kg}^{-1}$ wide bins of $800-500 \mathrm{hPa}$ averaged specific humidity.

a moist column with the variable $\tau$ the IFS produces more days with more rain and fewer days with less rain.

The analysis here of TCW versus precipitation rates builds up a consistent picture of the effect of changing the formulation of organized entrainment from $\epsilon_{\mathrm{org}}^{\mathrm{MC}}$ to $\epsilon_{\mathrm{org}}^{\mathrm{RH}}$. It is worth recalling the discussion in Bladé and Hartmann (1993) on their 'recharge-discharge' theory of the MJO. They suggest that the period of an MJO is set by the time it takes for the atmosphere to build up instability, or 'recharge', after stabilization through convection, or 'discharge', has occurred. Results here suggest that the modified IFS, with $\epsilon_{\mathrm{org}}^{\mathrm{RH}}$, is able to more effectively 'recharge' the atmosphere. More CAPE (not shown) and moisture (Figure 10) are able to build up in the tropical atmosphere without being released through convective precipitation; this results in suppressed convective conditions becoming more suppressed. The mechanisms described here lead to a better representation of the suppressed phase of the MJO and, since more instability is built up, lead to more vigorous deep convection when that instability is released, and hence also a better representation of the active phase of the MJO.

\subsection{Vertical structure of moisture}

The April 2009 case study discussed in H12 is used to test the hypothesis that the modified IFS, with $\epsilon_{\mathrm{org}}^{\mathrm{RH}}$, is better able to simulate the destabilization of the tropical atmosphere before a deep convective event. Figure 11 shows how the vertical structure of moisture changes from an initial state at the start of a 50-day period in March and April 2009 in IOW. This region is shown for consistency with section 4.1. The 20 - to 100-day band-pass-filtered OLR from the AVHRR satellite is also plotted (thick black line); the minimum in filtered OLR indicates the maximum strength of the convective event in that region.

Figure 11(a) shows, over IOW, the 'observed' change from the initial state in the vertical structure of moisture with data from ERA-Interim reanalysis. In mid March, approximately 25 days prior to the strong minimum in filtered OLR which occurred on 12 April, ERA-Interim displays a drying of more than $1.2 \mathrm{~g} \mathrm{~kg}^{-1}$ at mid levels, with a maximum at $600 \mathrm{hPa}$. This drying coincides with the maximum in filtered OLR, or the suppressed phase of 
(a) ERA-Interim/TRMM

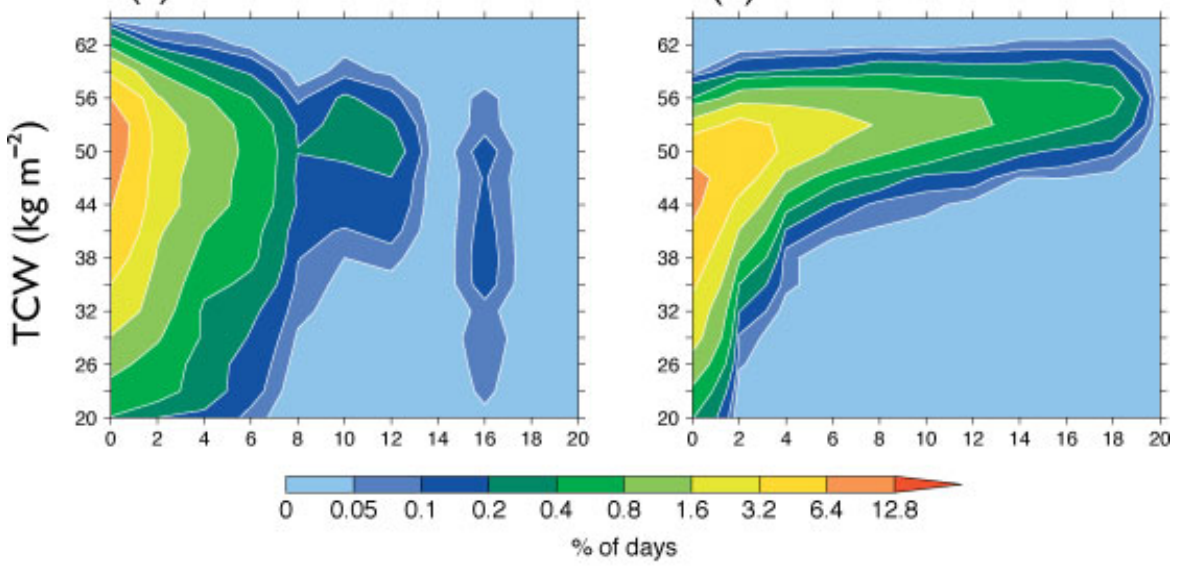

(b) OPER $\quad+24 h$ (d) (CAPE - CONV) ${ }^{t+24 h}$

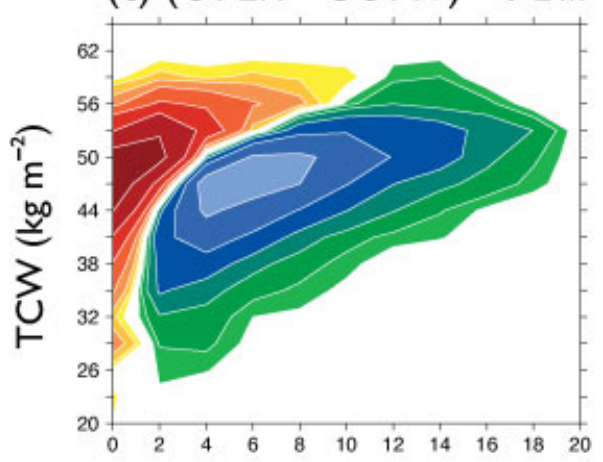

(e) (OPER - CAPE) $\quad$ t+24h

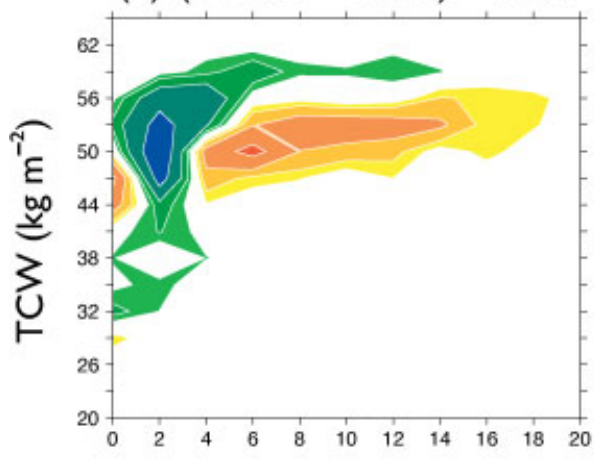

\section{(f) (OPER - ENTRN) $\quad t+24 h$}

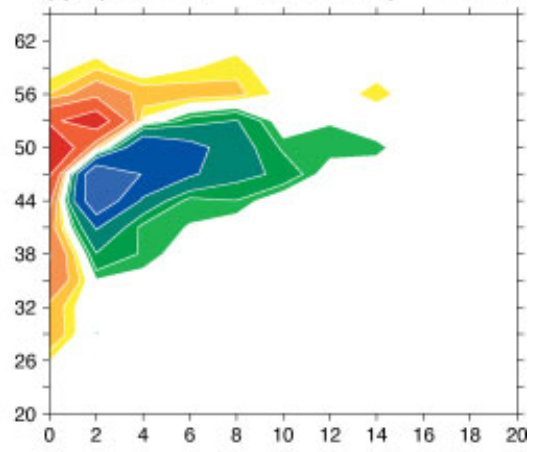

Precipitation $\left(\mathrm{mm}\right.$ day $\left.^{-1}\right)$

\begin{tabular}{cccc|c|c|c|c}
\hline & $\mid$ & $\mid$ & $\mid$ & $\mid$ & $\mid$ & $\mid$ & \\
-3.2 & -0.8 & -0.2 & -0.05 & 0.05 & 0.2 & 0.8 & 3.2 \\
$\%$ of days
\end{tabular}

Figure 10. Two-dimensional histogram of total column water (TCW; $\mathrm{kg} \mathrm{m}^{-2}$ ) versus precipitation ( $\mathrm{mm} \mathrm{d}^{-1}$ ) averaged over IOW from (a) ERA-Interim reanalysis and TRMM satellite data and (b) OPER at a 1-day forecast lead time, (c) difference between OPER and CONV (effect of Cy32r3), (d) CAPE and CONV (effect of $\epsilon_{\mathrm{org}}^{\mathrm{RH}}$ formulation), (e) OPER and CAPE (effect of $\tau$ ), (f) OPER and ENTRN (effect of $\epsilon_{\mathrm{org}}^{\mathrm{RH}}$ rate). The histograms are calculated for all days between May 2008 and April 2009.

the MJO. Approximately 10 days prior to the convective maximum there is a distinct moistening of more than $1.6 \mathrm{~g} \mathrm{~kg}^{-1}$ in the lower troposphere, which, with the passage of the wave, extends into the mid and upper troposphere, reaching $300 \mathrm{hPa}$ during mid April. In late April there was a further mid-troposphere drying with a maximum at $600 \mathrm{hPa}$, associated with the return to suppressed conditions over IOW. Figure 11(b) shows that, compared with ERAInterim, OPER successfully captures the mid-tropospheric drying before and after the convective maximum, but underestimates the lower-tropospheric moistening prior to the minimum in filtered OLR at a 1-day forecast lead time. The moist layer in OPER between 900 and $600 \mathrm{hPa}$ has strengthened considerably at a 5-day forecast lead time (Figure 11(c)).

At a 1-day forecast lead time, the effect of the modified Cy32r3 convective parametrization (Figure $11(\mathrm{~d})$ ) is, irrespective of the phase of the wave, to (a) moisten the surface, and a layer in the mid troposphere between 700 and $600 \mathrm{hPa}$ by more than $0.4 \mathrm{~g} \mathrm{~kg}^{-1}$, and (b) dry a layer in the lower troposphere between 900 and $800 \mathrm{hPa}$ by more than $0.4 \mathrm{~g} \mathrm{~kg}^{-1}$. This effect can be directly attributed to 

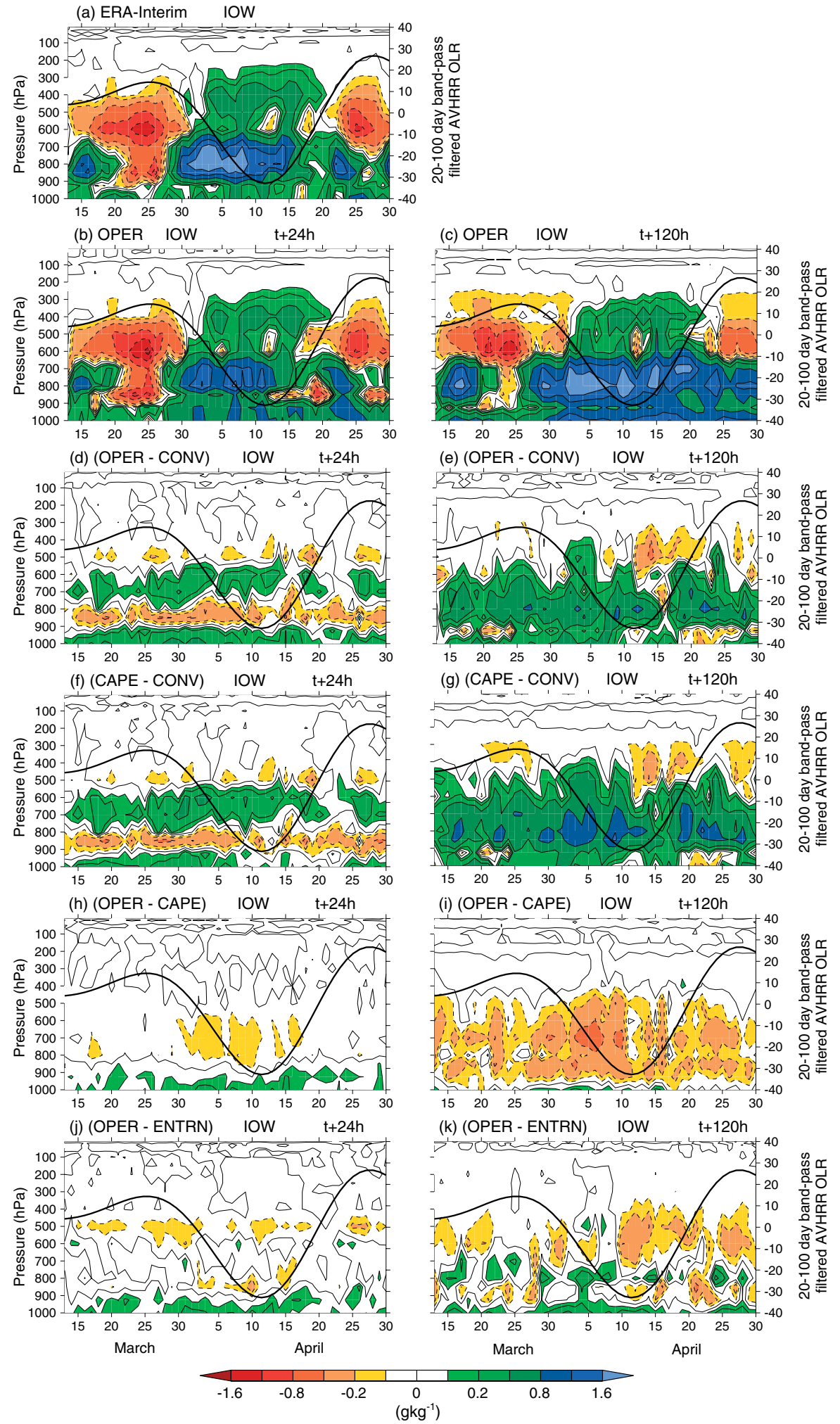

Figure 11. Change from the initial (12 March) state in the vertical structure of specific humidity averaged over IOW for a 50-day period in March and April 2009. (a) ERA-Interim, (b) and (c) OPER at a 1- and 5-day forecast lead time. Difference at a 1- and 5-day forecast lead time between OPER and CONV (effect of Cy32r3; (d, e)), CAPE and CONV (effect of $\epsilon_{\text {org }}^{\mathrm{RH}}$ formulation; (f, g)), OPER and CAPE (effect of $\tau$; (h, i)) and OPER and ENTRN (effect of $\epsilon_{\mathrm{org}}^{\mathrm{RH}}$ rate; $\left.(\mathrm{j}, \mathrm{k})\right)$. Area-averaged 20-100 day band-pass filtered OLR from the AVHRR satellite (thick black line).

$\epsilon_{\text {org }}^{\mathrm{RH}}$ (Figure 11(f)). At longer forecast lead times, however, the effect of $\epsilon_{\text {org }}^{\mathrm{RH}}$ is to moisten the tropical troposphere up to $400 \mathrm{hPa}$, with a maximum of more than $0.8 \mathrm{~g} \mathrm{~kg}^{-1}$ at approximately $800 \mathrm{hPa}$. Therefore, with $\epsilon_{\mathrm{org}}^{\mathrm{RH}}$, the IFS is able to build up considerably more moisture prior to the convective maximum associated with the MJO; Thayer-Calder and
Randall (2009) showed that this was a feature which is also apparent in SP-CAM. However, as forecast lead time increases, an effect of $\epsilon_{\mathrm{org}}^{\mathrm{RH}}$ is to moisten throughout the entire passage of the wave, resulting in an overestimation of mid-tropospheric moisture compared with ERA-Interim, especially in late April after the convective maximum has 
occurred. Halving the rate of $\epsilon_{\mathrm{org}}^{\mathrm{RH}}$ and changing to a variable $\tau$ had little effect on the change in moisture during the MJO event after 1 day of the forecast (Figure 11(h) and (j)). At a 5 -day forecast lead time, $\tau$ exhibits a drying in the middle and lower troposphere throughout the passage of the MJO, which compensates for the moistening effect of $\epsilon_{\mathrm{org}}^{\mathrm{RH}}$ and reduces the overestimation of humidity in Cy32r3. Results from the other equatorial regions are consistent with the picture of convective moistening during the passage of the April 2009 MJO event shown in Figure 11.

Figures 11 shows, by comparison to ERA-Interim, that OPER is able to capture the features of convective moistening during the passage of the MJO. Across each equatorial region in the Indo-Pacific, OPER, like ERA-Interim, exhibits midtropospheric drying during periods of maximum filtered OLR and mid-tropospheric moistening during periods of minimum filtered OLR. With $\epsilon_{\mathrm{org}}^{\mathrm{RH}}$, the IFS is able to better simulate the transition between the two phases. Approximately 10 days prior to the convective maximum, across all regions, the IFS with $\epsilon_{\mathrm{org}}^{\mathrm{RH}}$ starts to moisten the surface and lower troposphere. Increasing the entrainment in HadGEM3 integrations $(1.5 * \epsilon)$ had a similar effect to introducing $\epsilon_{\mathrm{org}}^{\mathrm{RH}}$ in the IFS (Klingaman, 2011).

\subsection{Temperature and moisture tendencies}

Continuing with the case study analysis, temperature ( $T_{\text {phys }}$; Eq. (1) ) and humidity ( $q_{\text {phys }}$; Eq. $\left.(2)\right)$ increments for IOW (Figure 12) from the IFS model physics are analysed. Since $\epsilon_{\mathrm{org}}^{\mathrm{RH}}$ is responsible for the advances in MJO simulation (H12), the analysis here focuses on the effect of $\epsilon_{\mathrm{org}}^{\mathrm{RH}}$ (CAPECONV), by examining the role of convective moistening by the sub-grid scale processes in the IFS during the same 50day period as in section 4.3 . The tendencies are calculated by summing contributions from shallow and deep convection (shal; deep), the cloud and turbulent diffusion schemes (cld ; turb) and, for heating only, the radiation scheme ( $\mathrm{rad})$. Although all the sub-grid scale processes are included in the analysis presented here, the largest contribution comes from the convection scheme:

$$
\begin{aligned}
& T_{\text {phys }}=T_{\text {shal }}+T_{\text {deep }}+T_{\text {cld }}+T_{\text {turb }}+T_{\text {rad }} \\
& q_{\text {phys }}=q_{\text {shal }}+q_{\text {deep }}+q_{\text {cld }}+q_{\text {turb }}
\end{aligned}
$$

A deep convective plume will moisten its immediate environment through the detrainment of moist air into the free troposphere. However, observational studies have shown that vigorous, precipitating convection is associated with a heat source and moisture sink in the mid troposphere (e.g. Lin and Johnson, 1996). The moisture sink is due to the removal of moisture from the atmosphere in the form of precipitation, and further drying of the atmosphere through compensating subsidence: the balance of the ascending, moist air with descending, dry air between convective plumes. These features are reproduced in the CAPE experiment; Figure 12 shows that in mid April, in IOW, during the period of maximum convection (minimum filtered OLR), there is a clear mid-tropospheric heating of more than $4 \mathrm{~K} \mathrm{~d}^{-1}$, and drying of more than $1.6 \mathrm{~g} \mathrm{~kg}^{-1} \mathrm{~d}^{-1}$. The heating and drying associated with the passage of the $\mathrm{MJO}$ are stronger at longer forecast lead times (Figure 12(b) and (f)).

Shallow convection does not penetrate as far into the free troposphere. It detrains more moist air out of the ascending plume, has weaker compensating descent and produces less precipitation than deep convection; therefore, the overall effect of shallow convection is to moisten the lower troposphere. Based on this, Figure 12(e) and (f) shows the moistening of the lower troposphere, and hence the occurrence of shallow convection, in mid March, during the days of maximum filtered OLR prior to the convective maximum. However, the strongest lower-tropospheric moistening, by more than $1.6 \mathrm{~g} \mathrm{~kg}^{-1} \mathrm{~d}^{-1}$, occurs during and in the days immediately after the convective maximum associated with the MJO, a feature which is slightly weakened at longer lead times (Figure 12(f)). The turbulent moisture flux contributes to the moistening of the upper boundary layer; however, the moistening from the convective tendency is dominant.

By comparing the difference between CAPE and CONV across all the equatorial regions, a consistent picture emerges of the effect of $\epsilon_{\mathrm{org}}^{\mathrm{RH}}$ on convective moistening by subgrid scale processes. At a 1-day forecast lead time, $\epsilon_{\mathrm{org}}^{\mathrm{RH}}$ dries (moistens) the lower troposphere (mid troposphere) between 1000 and $850(850$ and 500$) \mathrm{hPa}$; there is a further, weaker dry layer at $400 \mathrm{hPa}$ (Figure 12(g)). Additionally, at the 1-day forecast lead time, $\epsilon_{\mathrm{org}}^{\mathrm{RH}}$ cools the tropical troposphere through the entire period, apart from a small warming of the mid troposphere at or near the time of minimum filtered OLR (Figure 12(c)). At a 5-day forecast lead time, the near-surface drying between 1000 and $850 \mathrm{hPa}$ is still apparent throughout the 50-day period; when the filtered OLR is at a minimum, the entire troposphere dries, with a maximum at approximately $400 \mathrm{hPa}$. The moist layer, seen after the first day of the forecast, weakened and became confined to days when the filtered OLR was at a maximum (Figure 12(h)). The signal in the heating, observed after a 1-day forecast lead time, is consistent, but strengthened, at a 5-day lead time: when filtered OLR is at a maximum (minimum), there is cooling (heating) throughout the troposphere (in the mid troposphere), strongest between 400 and $500 \mathrm{hPa}$ (Figure 12(d)).

The dry and moist layers in the lower and mid troposphere at a 1-day forecast lead time show that the IFS, with $\epsilon_{\mathrm{org}}^{\mathrm{RH}}$, is producing less shallow, weak-precipitating convection and more convection detraining at mid levels during the entire 50-day period, a finding consistent with Figure 5. The fact that the IFS, with $\epsilon_{\mathrm{org}}^{\mathrm{RH}}$, is capable of moistening the mid levels will result in (a) a weaker trade inversion at the melting level during weak convective events and (b) a reduction in evaporation at those levels during strong convective events. Therefore, the heating and drying associated with the deep, penetrative convection of the MJO is strengthened. As the IFS moves through the forecast, with $\epsilon_{\mathrm{org}}^{\mathrm{RH}}$, the periods of strong convective activity are strengthened (more heating and drying), and the periods of weak convective activity become more suppressed (more cooling and moistening). This could explain how the IFS is able to maintain the amplitude of the MJO at longer forecast lead times with $\epsilon_{\mathrm{org}}^{\mathrm{RH}}$.

\section{Discussion and conclusions}

\subsection{Effect of individual components of Cy32r3}

Having established that the Cy32r3 convective parametrization was responsible for the improvements in MJO simulation (H12), the hindcast experiments were analysed to 

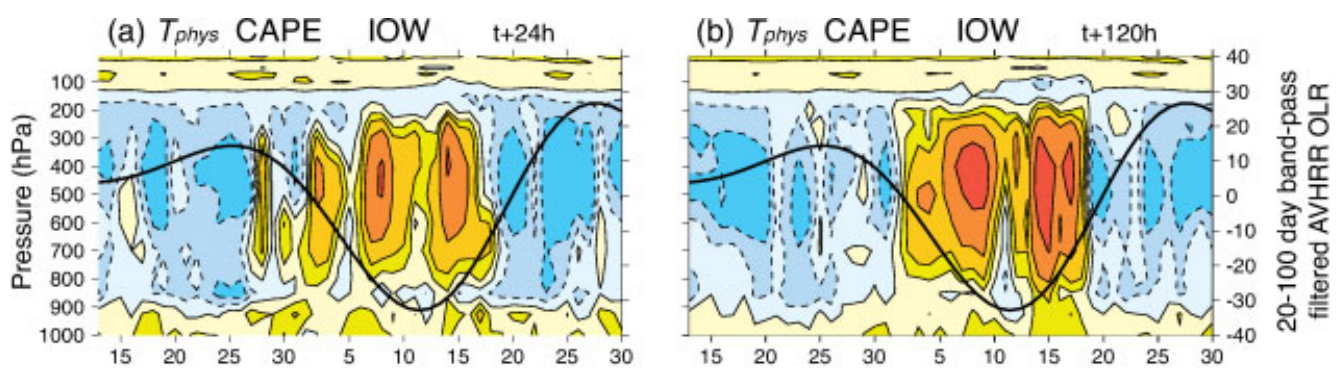

(c) $T_{\text {phys }}$ (CAPE - CONV) IOW $\mathrm{t}+24 \mathrm{~h}$

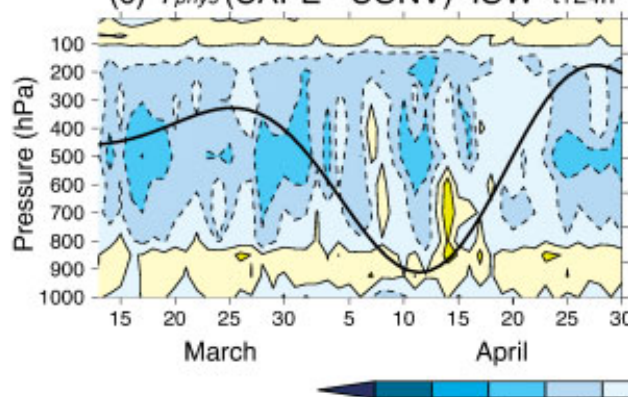

(d) $T_{\text {phys }}$ (CAPE - CONV) IOW t+120h

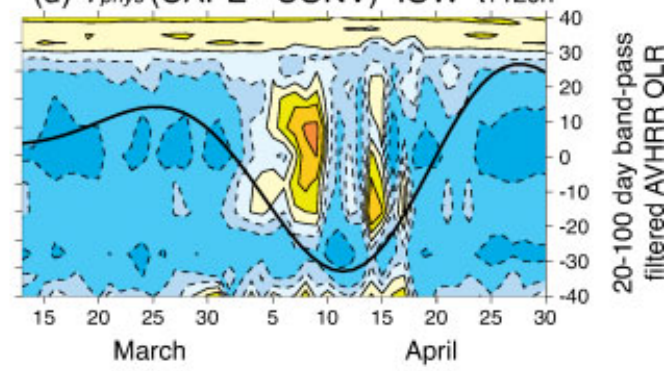

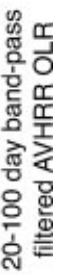

(K) day ${ }^{-1}$
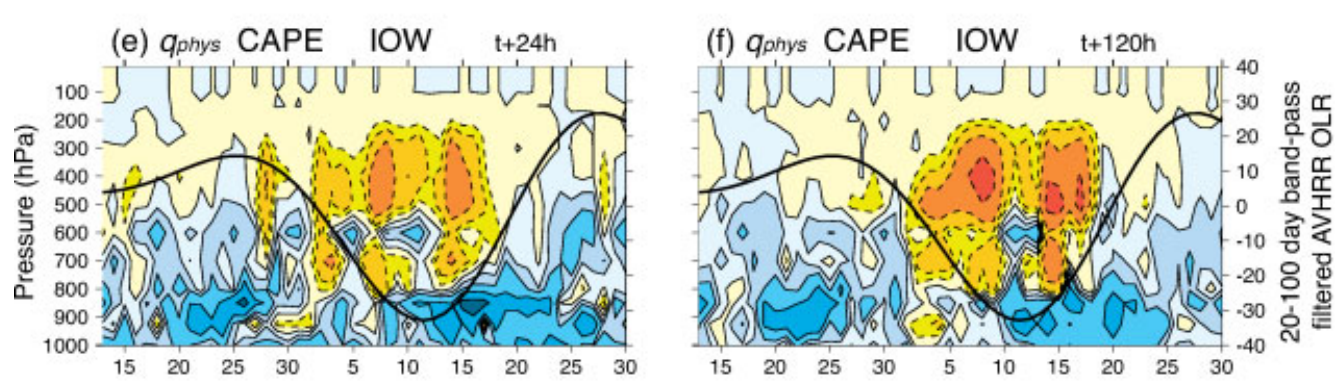

(g) qphys (CAPE - CONV) IOW t+24h

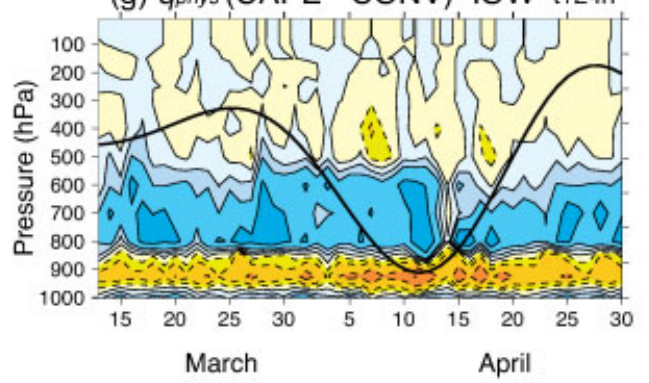

(h) $q_{\text {phys }}(\mathrm{CAPE}-\mathrm{CONV})$ IOW t+120h

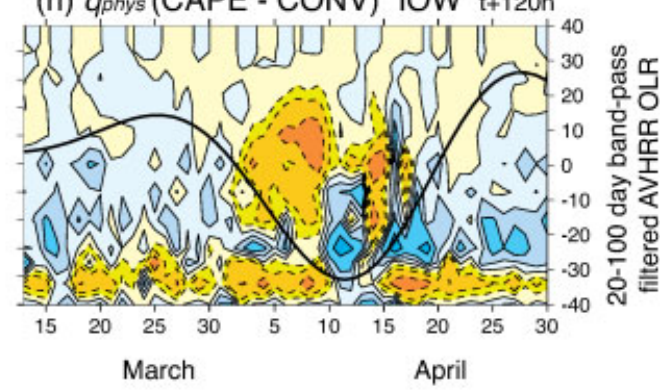

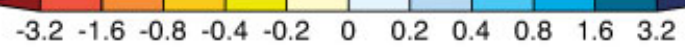

$\left(\mathrm{g} \mathrm{kg}^{-1}\right)$ day $^{-1}$

Figure 12. Heating ( $T_{\text {phys }}$, Eq. (1); top) and moistening ( $q_{\text {phys }}$, Eq. (2); bottom) tendencies from the IFS model physics, accumulated over a day and averaged over IOW. (a), (b), (e) and (f) show CAPE at a 1- and 5-day forecast lead time. (c), (d), (g) and (h) show the difference between CAPE and CONV (effect of $\epsilon_{\mathrm{org}}^{\mathrm{RH}}$ formulation) at a 1- and 5-day forecast lead time. Area-averaged 20- to 100-day band-pass-filtered OLR from the AVHRR satellite ( $\mathrm{W} \mathrm{m} \mathrm{m}^{-2}$; thick black line). Negative values are shown by dashed contours.

determine which part of the modified scheme, the variable $\tau$ or the entrainment formulation $\left(\epsilon_{\mathrm{org}}^{\mathrm{RH}}\right)$, was responsible. Results have conclusively shown that changing the control on convection, by modifying the formulation of entrainment from $\epsilon_{\mathrm{org}}^{\mathrm{MC}}$ to $\epsilon_{\mathrm{org}}^{\mathrm{RH}}$, was the key to the advances in MJO simulation described above.

Contrastingly, analysis of the ENTRN hindcast experiment showed that, within the $\epsilon_{\text {org }}^{\mathrm{RH}}$ formulation, the simulation of the MJO was not sensitive to this (approximate) 25\% reduction in the rate of entrainment. A relative-humiditydependent formulation for organized entrainment led to an IFS that produced a more realistic distribution of precipitation (Figure 4) and a trimodal structure of tropical cloud, with more cumulus congestus moistening the mid troposphere (Figure 5). This resulted in an IFS that was able to increase convective activity in the Maritime Continent and West Pacific without producing deep, penetrative convection too often (sections 3.1 and 3.2). These results suggest that, with $\epsilon_{\mathrm{org}}^{\mathrm{RH}}$, the IFS has improved its simulation of the MJO through a better representation of the transition from shallow to deep convection. The physical mechanisms through which this was achieved were the focus of section 4 
and will be addressed in more detail below. Moving to a variable CAPE adjustment time-scale had a small compensating effect on the mean state of the IFS but little overall impact on the simulation of the MJO (H12). However, the value of the primary peak in the PDF of the variable $\tau$ was close to the previous, resolution-dependent constant. This may account for the lack of impact on the simulation of the MJO.

\subsection{Impact on the mean state}

The initial focus here has been to identify how the $\epsilon_{\mathrm{org}}^{\mathrm{RH}}$ formulation has modified the mean state of the IFS, and to understand how that modified mean state may lead to, or indeed result from, a better representation of the MJO. The main changes to the mean state of the IFS with the introduction of the relative-humidity-dependent formulation for organized entrainment are:

(a) a cooling through the depth of the tropical troposphere, largest in the upper troposphere (Figure 1), likely to be as a result of less active convection that does not penetrate as deep into the upper troposphere;

(b) an associated increase in the occurrence of cumulus congestus clouds detraining in the mid troposphere (Figure 5);

(c) a moistening of the tropical mid troposphere (Figure 2), likely to be due to (b);

(d) a reduction in the magnitude of the subtropical jets above and equatorward of their maxima (not shown), a dynamical response to (a)-(c) (section 2.2);

(e) a more realistic distribution of precipitation rates, compared with TRMM observations (Figure 4).

Analysis of the physical tendencies from the IFS revealed that the convective parametrization, more specifically the deep convection scheme, contributed to the change in the vertical structure of the zonal-mean temperature in the Tropics (Figure 6). The modified mean state in zonal wind discussed in section 3.1 cannot be directly attributed to the convection scheme, but is likely a consequence of the modified vertical structure in temperature. The increments in moisture from the dynamics and from convective parametrization are opposite in sign (Figure 7): the dynamics (convection scheme) increments moisten (dry) at the surface across the entire Tropics and dry (moisten) the mid troposphere, with maxima near the Equator.

\subsection{Physical processes at work}

The modified mean state of the IFS reported here, with the introduction of $\epsilon_{\mathrm{org}}^{\mathrm{RH}}$, results in an IFS that is better able to represent the transition from shallow to deep convection through more effective preconditioning of the mid levels. These processes could contribute to the improved representation of the MJO in the IFS with the modified $\epsilon_{\mathrm{org}}^{\mathrm{RH}}$ formulation. The application of process-based diagnostics in section 4 explored this hypothesis and examined the role of convective moistening in the simulation of the MJO. This paper has shown that the introduction of $\epsilon_{\mathrm{org}}^{\mathrm{RH}}$ led to a better representation of the MJO through the mechanisms listed here and described in detail below: (a) the introduction of a tropospheric moisture control on deep convection;

(b) a more realistic, precipitation-moisture relationship, due to (a);

(c) a better simulation of the transition from shallow to deep convection by the moistening, or preconditioning, of the mid troposphere, due to (b).

(a) Tropospheric moisture control on convection. Through the commonly used CAPE closure for deep convection, the simulation of penetrative convective plumes in NWP models is often closely linked to the amount of CAPE in an atmospheric column. The build-up of tropospheric moisture, however, has been shown to be more important than the build-up of CAPE for the accurate simulation of the transition to deep convection (e.g. Redelsperger et al., 2002; Derbyshire et al., 2004; Waite and Khouider, 2010). CAPE is mainly sensitive to moisture in the boundary layer; a CAPE closure for deep convection was held responsible for the missing link between environmental moisture and convective mass transport, which led to a poor simulation of the MJO in CAM (Thayer-Calder and Randall, 2009). The CAPE formulation in the IFS does show some sensitivity to the environment by using the updraught temperature, produced from the full entrainment rate, in its calculation. However, the work presented in this paper supports the shift from CAPE-sensitive to moisture-sensitive formulations for convection. The post-Cy32r3 IFS still has a CAPE closure for deep convection, but in recognition of the importance of environmental humidity the $\epsilon_{\mathrm{org}}^{\mathrm{RH}}$ formulation increases the sensitivity of convection to free-tropospheric moisture. By implementing a formulation that increases entrainment in dry environmental conditions and decreases it in a moist environment, the intensity of convection is controlled by the amount of water in the atmospheric column, not just the moisture in the boundary layer.

However, it is not just the humidity-dependent factor in the formulation for organized entrainment which is important to the simulation of cumulus convection; de Rooy et al. (2012) show that it is also crucial that the overall entrainment rate is large. Strong entrainment at the cloud base, necessitating a vertical scaling function which decreases with height, is also shown to provide strong sensitivity to environmental moisture. Increasing the minimum rate of entrainment in CAM was also shown to improve intraseasonal variability and the simulation of the MJO (Hannah and Maloney, 2011).

(b) Modified precipitation-moisture relationship. The introduction of $\epsilon_{\mathrm{org}}^{\mathrm{RH}}$ changed the relationship between precipitation and moisture in the IFS (section 4.1), a relationship shown to be highly nonlinear in observations (Bretherton et al., 2004), but very important to the simulation of the MJO (Kim et al., 2009; Thayer-Calder and Randall, 2009; Zhu et al., 2009). In general, the modified relationship between tropical rainfall and column humidity is more realistic compared with observations. With $\epsilon_{\mathrm{org}}^{\mathrm{RH}}$, the IFS is able to accumulate more moisture in the atmospheric column before it starts producing precipitation. This results in: (a) fewer occurrences of low-humidity environments producing moderate precipitation rates, i.e. too frequent weak convection; and (b) heavy precipitation occurring only when the atmospheric column is sufficiently moist. The former is likely be the physical mechanism through which the modified IFS, with $\epsilon_{\mathrm{org}}^{\mathrm{RH}}$, no longer exhibits an unrealistic preferred 
rainfall peak of approximately $10 \mathrm{~mm} \mathrm{~d}^{-1}$ (Figure 4); and the latter is likely to be a physical mechanism through which the IFS is better able to simulate the transition from shallow to deep convection through the build-up of mid-tropospheric moisture.

The results from this study suggest that tropospheric moisture control on precipitation is a necessary process for a model to capture if it is to be successful at simulating intraseasonal variability (Figures 8 and 9). This adds weight to the existing evidence in the literature that the relationship between precipitation and humidity is important to the representation of the MJO in numerical simulations. Kim et al. (2009) applied 'process-based' diagnostics to output from eight climate models and showed that the dependence of precipitation on the vertical structure of tropospheric humidity was a feature common among models that produced the most accurate simulations of the MJO.

However, the modified precipitation-moisture relationship in the post-Cy32r3 IFS is by no means perfect. In versions of the IFS with $\epsilon_{\mathrm{org}}^{\mathrm{RH}}$, at the humid end of the distribution precipitation increases exponentially with column water vapour. This is a feature that the IFS shares with SP-CAM, and which is suggested to be crucial to the successful simulation of the MJO (Zhu et al., 2009). However, in both the IFS and SP-CAM, this results in an overestimation of precipitation in a humid environment compared with observations.

(c) Improved preconditioning of the tropical atmosphere. The modified precipitation-moisture relationship and tropospheric control on moisture has led to an IFS that has increased the sensitivity of deep convection to the amount of water vapour in the atmospheric column. With the $\epsilon_{\mathrm{org}}^{\mathrm{RH}}$ formulation there is an increase in dry-air entrainment in low-humidity environments. The dilution of a convective plume by dry air will reduce net condensation and buoyancy, inhibit the development of deep cumulonimbus and result in lower cloud-top heights. Therefore, with $\epsilon_{\mathrm{org}}^{\mathrm{RH}}$, convective plumes ascending in a dry environment will not penetrate as high into the upper troposphere; fewer deep convective plumes penetrating into the upper troposphere results in a cooling there (Figure 1). The overestimation of the depth and intensity of convection in dry conditions has been reported as a possible cause for poor simulations of the MJO (e.g. Lin et al., 2006), and proved a tough test for a model's moist physics to represent. However, dry-air entrainment has previously been shown to be an effective mechanism through which tropospheric moisture modulates cloud depth in observational studies (Holloway and Neelin, 2009) and cloud-resolving numerical simulations (Waite and Khouider, 2010).

An effect of the lower cloud-top heights, produced through increased dry-air entrainment, is that more convective plumes will terminate near the melting layer. The melting layer is a thin stable layer at the zero-degree isotherm (approximately $500 \mathrm{hPa}$ in the Tropics) that is maintained by heat absorbed by the melting of precipitation from ice to liquid phase (Johnson et al., 1999). The occurrence of more clouds which terminate near this stable layer and the melting of the associated frozen precipitation result in a loss of heat and an increase in stability at this level. This is suggested as the process through which $\epsilon_{\mathrm{org}}^{\mathrm{RH}}$ increases cumulus congestus in the IFS (Figure 5). A strong stable layer in the middle troposphere will result in more convective plumes detraining there. A similar effect, albeit by a different mechanism, has been seen in GCM simulations; Inness et al. (2001) showed that improving the representation of the freezing level, through a finer vertical resolution, led to a more realistic trimodal distribution of cloud compared with observation.

The increase in cumulus congestus detraining at the melting layer acts to moisten the mid troposphere (Figure 2), slowly eroding the stable layer. As the cumulus congestus deepens, the moistening penetrates further into the free troposphere. Due to the modified tropospheric moisture control on precipitation described above, deep cumulonimbus is only triggered when the environment is sufficiently humid (Figures 8 and 9). Therefore, during this transition phase more moisture (Figure 10) and CAPE can build up, with the convection scheme removing less moisture from dry or moderately moist columns. Waite and Khouider (2010) suggest that, for the transition from shallow to deep convection, the build-up of free tropospheric moisture is more important than the build-up of CAPE. In their cloudresolving simulations, if there is sufficient moisture in the mid troposphere then deep convection can be triggered with relatively low CAPE.

A corollary of the tropospheric moisture control on convection is that, once deep cumulonimbus does develop, it does so in a moist environment. When convection occurs in a moist environment, the entrainment of air into the convective plume does not result in significant dilution or loss of buoyancy, but rather strengthens the convective heating. The compensating subsidence between ascending convective plumes results in the formation of a largescale circulation, which is maintained by a mechanism referred to by Grabowski and Moncrieff (2004) as the moisture-convection feedback. This moisture-convection effect has also been shown to be important to the simulation the $\mathrm{MJO}$ in an aquaplanet configuration (e.g. Raymond and Fuchs, 2009). The large-scale circulation deepens the moist layer in the free troposphere and increases the compensating subsidence, which in turn strengthens the large-scale circulation. While the findings of this study support the moisture-convection feedback as being a physical mechanism which contributes to better maintaining the intraseasonal variability in the modified IFS, it does not negate the need for other theories of the MJO. For example, both cloud radiation and surface wind evaporation feedbacks, while not the focus of this study, have also been shown to be important in maintaining the strong moisture anomalies associated with the MJO (e.g. Raymond et al., 2009; Sobel et al., 2010). It is likely that parts of several theories of the MJO will be important to its initiation, maintenance and evolution.

Recognizing the role that thermodynamic feedback processes play in the initiation and evolution of the MJO, Bladé and Hartmann (1993) proposed a 'recharge-discharge' theory for the MJO. According to their theory, the period of the MJO is set by the time it takes the atmosphere over the tropical Indian Ocean to destabilize or 'recharge'. The build-up of moisture through low- and mid-level cloud increases instability until finally deep convection is triggered and the atmosphere stabilizes again. This stabilization, or 'discharge', removes the moisture from the tropical atmosphere and returns it to a dry, suppressed regime (see also Yano and Plant, 2012). Consistent with this theory, the build-up of moisture in the lower and middle troposphere prior to the convective maximum associated with the MJO 


\section{C. Hirons et al.}

(Figure 9), suggests that the modified IFS is better able to 'recharge' the tropical atmosphere. Through increasing the stability of the atmosphere, dry-air entrainment is a crucial mechanism through which the modified IFS inhibits the premature development of deep convection, resulting in an improved representation of the suppressed phase of the MJO. Therefore, with $\epsilon_{\mathrm{org}}^{\mathrm{RH}}$, there is a clearer distinction between active and suppressed conditions associated with the MJO (Figure 12), as well as a smoother transition between the regimes.

Making the organized entrainment rate in the IFS parametrization for deep convection more sensitive to the environmental humidity surrounding the convective plume has confirmed the hypothesis that the modified IFS is better able to simulate the transition from shallow to deep convection. With $\epsilon_{\mathrm{org}}^{\mathrm{RH}}$, the IFS starts to produce precipitation with more water in the atmospheric column (Figure 8) and a mid troposphere that is more moist (Figure 9). This allows the build-up of more CAPE and moisture (Figure 10) without much release or removal from the atmospheric column through convective precipitation. The modified relationship between precipitation and moisture allows for better preconditioning of the lower and mid troposphere prior to a large convective event. During the passage of an MJO event in April 2009, with $\epsilon_{\mathrm{org}}^{\mathrm{RH}}$ the IFS was able to moisten the lower troposphere in the days prior to the convective maximum associated with the MJO (Figure 11). The moistening of mid levels (Figure 12) decreases the stability of the mid troposphere at the melting level, which enables the following convective plumes to overcome the stable layer and penetrate into the upper troposphere. As well as simulating the transition from shallow to deep convection through convective preconditioning by cumulus congestus at mid levels, with $\epsilon_{\text {org }}^{\mathrm{RH}}$ the distinction between suppressed and active conditions is larger. Suppressed conditions become more suppressed and active conditions more active (Figure 12). However, in the case of the active phase of the MJO, this has resulted in an overestimation of precipitation compared with observations.

\section{Acknowledgements}

The author would like to thank the National Environmental Research Council (NERC) for providing the PhD scholarship that made this work possible, and ECMWF for their support of this work.

\section{References}

Bechtold P, Köhler M, Jung T, Doblas-Reyes F, Leutbecher M, Rodwell MJ, Vitart F, Balsamo G. 2008. Advances in simulating atmospheric variability with the ECMWF model: from synoptic to decadal timescales. Q. J. R. Meteorol. Soc. 134: 1337-1351.

Bladé I, Hartmann DL. 1993. Tropical intraseasonal oscillations in a simple nonlinear model. J. Atmos. Sci. 50: 2922-2939.

Bretherton CS, Peters ME, Back LE. 2004. Relationships between water vapor path and precipitation over the tropical oceans. J. Climate 17: 1517-1528.

Derbyshire SH, Beau I, Bechtold P, Grandpeix JY, Piriou JM, Redelsperger JL, Soares PMM. 2004. Sensitivity of moist convection to environmental humidity. Q. J. R. Meteorol. Soc. 130: 3055-3079.

de Rooy WC, Bechtold P, Frölich K, Hohenegger C, Jonker H, Mironov D, Siebesma AP, Teixeira J, Yano JI. 2012. Entrainment and detrainment in cumulus convection: an overview. Q. J. R. Meteorol. Soc., DOI: 10.1002/qj.1959.

Grabowski WW. 2003. MJO-like coherent structures: sensitivity simulations using the cloud-resolving convection parameterization (CRCP). J. Atmos. Sci. 60: 847-864.

Grabowski WW, Moncrieff MW. 2004. Moisture-convection feedback in the tropics. Q. J. R. Meteorol. Soc. 130: 3081-3104.

Hannah WM, Maloney ED. 2011. The role of moisture-convection feedbacks in simulating the Madden-Julian Oscillation. J. Climate 24: 2754-2770.

Hirons LC, Inness P, Vitart F, Bechtold P. 2012. Understanding advances in the simulation of intraseasonal variability in the ECMWF model. Part I. The representation of the MJO. Q. J. R. Meteorol. Soc., DOI: 10.1002/qj.2060.

Holloway C. 2011. 'Cascade: high-resolution large-domain simulations of tropical convection'. In YOTC International Science Symposium and 8th AMY Workshop, Beijing: China.

Holloway CE, Neelin JD. 2009. Moisture vertical structure, column water vapour, and tropical deep convection. J. Atmos. Sci. 66: 1665-1683.

Inness PM, Slingo JM, Woolnough SJ, Neale RB, Pope VD. 2001. Organization of tropical convection in a GCM with varying vertical resolution: implications for the simulation of the Madden-Julian Oscillation. Clim. Dynam. 17: 777-793.

Inness PM, Slingo JM, Guilyardi E, Cole J. 2003. Simulation of the Madden-Julian Oscillation in a coupled general circulation model. Part II. The role of the basic state. J. Climate 16: 365-382.

Johnson RH, Rickenbach TM, Rutledge SA, Ciesielski PE, Schubert WH. 1999. Trimodal characteristics of tropical convection. J. Climate 12 2397-2418.

Kim D, Sperber K, Stern W, Waliser D, Kang I-S, Maloney E, Wang W, Weickmann K, Benedict J, Khairoutdinov M, Lee M-I, Neale R, Suarez M, Thayer-Calder K, Zhang G. 2009. Application of MJO simulation diagnostics to climate models. J. Climate 22: 6413-6436.

Klingaman N. 2011. 'Using a case-study approach to improve the MJO in the Hadley Centre climate model (HadGEM)'. In YOTC International Science Symposium and 8th AMY Workshop, Beijing: China.

Lin JL, Kiladis GN, Mapes BE, Weickmann KM, Sperber KR, Lin W, Wheeler MC, Schubert SD, Genio AD, Donner LJ, Emori S, Gueremy JF, Hourdin F, Rasch PJ, Roeckner E, Scinocca JF. 2006. Tropical intraseasonal variability in 14 IPCC AR4 climate models. Part I. Convective signals. J. Climate 19: 2665-2690.

Lin X, Johnson RH. 1996. Heating, moistening and rainfall over the Western Pacific Warm Pool during TOGA COARE. J. Atmos. Sci. 53: 3367-3383.

Ray P, Zhang C, Moncrieff MW, Dudhia J, Caron JM, Leung LR, Bruyere C. 2011. Role of the atmospheric mean state on the initiation of the Madden-Julian Oscillation in a tropical channel model. Clim. Dynam. 36: 161-184.

Raymond DJ. 2000. Thermodynamic control of tropical rainfall. Q. J. $R$. Meteorol. Soc. 126: 889-898.

Raymond DJ, Fuchs Z. 2009. Moisture modes in the Madden-Julian Oscillation. J. Climate 22: 3031-3046.

Raymond DJ, Sessions SL, Sobel AH, Fuchs Z. 2009. The mechanics of gross moist stability. J. Adv. Model. Earth Syst. 1: article 9.

Redelsperger JL, Parsons DB, Guichard F. 2002. Recovery processes and factors limiting cloud-top height following the arrival of a dry intrusion observed during TOGA-COARE. J. Atmos. Sci. 59: 2438-2457.

Sobel AH, Maloney ED, Bellon G, Frierson DM. 2010. Surface fluxes and tropical intraseasonal variability: a reassessment. J. Adv. Model. Earth Syst. 2: article 2.

Sperber KR, Gualdi S, Legutke S, Gayler V. 2005. The Madden-Julian Oscillation in ECHAM4 Coupled and Uncoupled GCMs. Clim. Dynam. 25: 117-140.

Thayer-Calder K, Randall DA. 2009. The role of convective moistening in the Madden-Julian Oscillation. J. Atmos. Sci. 66: 3297-3312.

Waite ML, Khouider B. 2010. The deepening of tropical convection by congestus preconditioning. J. Atmos. Sci. 67: 2601-2615.

Waliser DE, Sperber KR, Hendon HH, Kim D, Maloney ED, Wheeler MC, Weickmann KM, Zhang C, Donner L, Gottschalck J, Higgins W, Kang IS, Legler D, Moncrieff M, Schubert S, Stern W, Vitart F, Wang B, Wang W, Woolnough SJ. 2009. MJO simulation diagnostics. J. Climate 22: 3006-3030.

Yano JI, Plant R. 2012. Finite departure from convective quasiequilibrium: periodic cycle and discharge-recharge mechanism. Q. J. R. Meteorol. Soc. 138: 626-637.

Zhang C, Dong M, Gualdi S, Hendon HH, Maloney ED, Marshall A, Sperber KR, Wang W. 2006. Simulations of the Madden-Julian Oscillation in four pairs of coupled and uncoupled global models. Clim. Dynam. 27: 573-592.

Zhu H, Hendon HH, Jakob C. 2009. Convection in a parameterized and superparameterized model and its role in the representation of the MJO. J. Atmos. Sci. 66: 2796-2811. 